\title{
The impact of peer personality on academic achievement
}

Golsteyn, Bart H H ; Non, Arjan ; Zölitz, Ulf

\begin{abstract}
This paper provides evidence of a novel facet of peer effects by showing that peer personality influences academic achievement. We exploit random assignment of students to university sections and find that students perform better in the presence of persistent peers. The impact of peer persistence is enduring, as students exposed to persistent peers at the beginning of their studies continue to achieve higher grades in subsequent periods. The personality peer effects that we document are distinct from other observable peer characteristics and suggest that peer personality traits affect human capital accumulation.
\end{abstract}

DOI: https://doi.org/10.1086/712638

Posted at the Zurich Open Repository and Archive, University of Zurich

ZORA URL: https://doi.org/10.5167/uzh-205412

Journal Article

Published Version

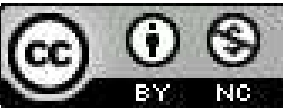

The following work is licensed under a Creative Commons: Attribution-NonCommercial 4.0 International (CC BY-NC 4.0) License.

Originally published at:

Golsteyn, Bart H H; Non, Arjan; Zölitz, Ulf (2021). The impact of peer personality on academic achievement. Journal of Political Economy, 129(4):1052-1099.

DOI: https://doi.org/10.1086/712638 


\section{The Impact of Peer Personality on Academic Achievement}

\section{Bart H. H. Golsteyn}

Maastricht University

\section{Arjan Non}

Erasmus University Rotterdam

\section{Ulf Zölitz}

University of Zurich

This paper provides evidence of a novel facet of peer effects by showing that peer personality influences academic achievement. We exploit random assignment of students to university sections and find that students perform better in the presence of persistent peers. The impact of peer persistence is enduring, as students exposed to persistent peers at the beginning of their studies continue to achieve higher grades in subsequent periods. The personality peer effects that we document are distinct from other observable peer characteristics and suggest that peer personality traits affect human capital accumulation.

\section{Introduction}

A steadily growing body of literature in economics, psychology, and sociology recognizes the importance of people's personality traits on their life's

We received helpful comments from Armin Falk, Jan Feld, Wolter Hassink, Ingo Isphording, Fabian Kosse, Nico Rasters, Nicolás Salamanca, Giuseppe Sorrenti, Tom Stolp, Dirk Tempelaar, and seminar participants at briq (Institute on Behavior and Inequality), the University of

Electronically published March 2, 2021

[ joumal of Political Fconomy, 2021, vol. 129, no. 4]

(2) 2021 by The University of Chicago. This work is licensed under a Creative Commons Attribution-NonCommercial 4.0 International License (CC BY-NC 4.0), which permits non-commercial reuse of the work with at tribution. For commercial use, contact journal permissions@ press. uchicago.edu 0022-3808/2021/12904-0003\$10.00 
trajectory. Personality traits predict many significant outcomes in life, including educational attainment, earnings, employment, and health, as well as participation in risky behavior and crime. ${ }^{1}$ Although evidence on the importance of personality traits is accumulating, there is virtually no research on the extent to which individuals' personality traits affect other people in their social environment. The literature on peer effects, which is dedicated to identifying social spillovers, has established that peer characteristics such as race, gender, and test scores affect the accumulation of human capital. ${ }^{2}$ Surprisingly, the literature neglects the question of whether the personality of peers affects educational outcomes.

In this paper, we test whether peer personality affects performance in education, using data from a Dutch business school. Two key features make this institution the ideal place to study peer effects. First, students are required to spend a significant amount of study time in small teaching sections of up to 16 students. These sections provide us with natural peer groups in which students engage in meaningful social interactions through solving problems and discussing the literature. Second, students are randomly assigned to these sections, conditional on scheduling constraints. In most other educational settings, students are tracked or self-select into peer groups. Random assignment allows us to overcome this fundamental

Cologne, the University of Munich, Maastricht. University, Utrecht University, the Max Planck Institute for Research on Collective Goods (Bonn), the University of Bamberg, the University of Zurich, HEC (Faculty of Business and Economics) Lausanne, the University of Reading, the University of Sheffield, the Tinbergen Institute (Amsterdam), RWTH (Rheinisch-Westfälische Technische Hochschule) Aachen University, Bureau for Economic Policy Analysis (The Hague), and conference participants at the briq/IZA (Institute for Labor Economics) workshop on socioemotional skills, the second IZA education workshop, the workshop on Measurement of Individual Heterogeneity and Its Use in Economic Models (Bonn), the European Economic Association (Cologne), the European Society for Population Economics (Antwerp), the International Workshop on Applied Economics of Education (Catanzaro), the Institute for the Study of Labor/Society of Labor Economists (Buch am Ammersee), the Economics of Education workshop (Maastricht), the Royal Economic Society (Sussex), the European Association of Labour Economists (Lyon), and the Society of Labor Economists (Toronto). Golsteyn acknowledges financial support from the Netherlands Organization for Scientific Research (NWO Vidi grant 452-16-006). We thank Maximilian Mähr, Sophia Wagner, and Jeffrey Yusof for providing outstanding research assistance and the Department of Education Research and Development for sharing the data. Information on data access is provided as supplementary material online.

' An often-used taxonomy in personality psychology is the Big Five. This entails openness to experiences, conscientiousness, extraversion, agreeableness, and neuroticism. Big Five traits are predictive of many outcomes in life, including schooling, wages, crime, teenage pregnancy, and longevity. Generally, conscientiousness and neuroticism are more predictive than the other traits (see Borghans et al. 2008; Almlund et al. 2011). Borghans et al. (2016) show that personality traits have predictive power over and above pure cognition for life outcomes. Regarding economic preference parameters, recent studies reveal that time preferences (Golsteyn, Grönqvist, and Lindahl 2014; Åkerlund et al. 2016), risk attitudes (Dohmen et al. 2011), and social preferences (Dohmen et al. 2009) predict outcomes in life such as educational attainment, wages, and health outcomes.

${ }^{2}$ Sacerdote (2011) provides a review of the literature. 
selection problem that typically plagues the identification of causal peer effects.

We measure personality at the beginning of the students' academic careers, before their assignment to the groups in which we test for peer effects. This avoids the simultaneity problem arising from the fact that peers may influence students' self-reported personality. We collect four distinct measures of students' personality traits related to education: (1) persistence, which we show is a facet of grit (Duckworth et al. 2007) and which captures how much students keep trying to solve a problem even if it is challenging, (2) self-confidence, which measures students' belief in their ability to do well and succeed in their studies, (3) anxiety, which we show is a facet of neuroticism (a "Big Five" personality factor) and reflects how worried and nervous students are about succeeding in their studies, and (4) risk attitude, which captures people's willingness to engage in risky behaviors. After combining students' self-assessed measures of these traits with their administrative records on grades, we observe 17,512 studentcourse observations of 4,383 students from five study cohorts.

Our results show that students who were randomly assigned to a group of more persistent peers attain higher exam grades in centrally graded exams. A 1 standard deviation increase in average peer persistence raises grades by $1.8 \%$ of a standard deviation. The impact of a 1 standard deviation increase in peer persistence is approximately twice as large as that of a 1 standard deviation increase in peer GPA (grade point average), as identified by Feld and Zölitz (2017) in the same setting. We further find that exposure to risk-tolerant peers negatively affects performance. A 1 standard deviation increase in peers' risk tolerance lowers grades by $1.1 \%$ of a standard deviation. Peer anxiety and self-confidence do not significantly affect performance. While the impact of peer persistence remains statistically significant after correction for multiple-hypothesis testing, the impact of peer risk attitude on performance does not remain significant after the correction. When looking at the heterogeneity of peer effects, we find that both students with high and those with low own persistence benefit from having persistent peers. Students with a middle level of persistence are not affected. ${ }^{3}$

Given that personality traits are likely to be correlated with other characteristics, we test whether the inclusion of peer GPA, peer math and statistics entry test scores, peer gender, and peer nationality affects our results. Our

\footnotetext{
${ }^{3}$ Note that these results seem to suggest that grouping high- and low-persistence students together could be an effective way to reduce inequality in academic achievement. However, Carrell, Sacerdote, and West (2013) caution against this type of policy recommendation, because (1) we may not have sufficient underlying support in the data and (2) the reassignment may change the underlying structure of social interactions between students that generate peer effects. An experimental validation of such policy implications would provide important additional insights.
} 
conclusions on the impact of peer personality are not affected by the inclusion of these observable peer characteristics. These results suggest that the effect of peer personality is distinct from peer achievement and other observable peer characteristics.

What are the mechanisms behind these effects? Persistent peers may raise performance, for example, through influencing study efforts, improving group functioning, motivating teachers, or shaping social networks. To better understand the underlying mechanisms, we analyze (1) the effect of peer personality on students' self-reported study hours, (2) the effect on students' evaluations of courses and teachers, (3) how peer personality interacts with teacher quality, (4) whether performance in parallel and subsequent courses is affected, and (5) whether students with more persistent peers are more likely to interact with persistent students. While we do not find that persistent peers affect self-reported study hours or students' perceptions of the teacher, we do find that peer personality appears to be complementary to teacher quality. Moreover, we find that the effect of persistent peers is nontransient: exposure to persistent peers also increases grades in future periods. This suggests that our results are driven not by a transfer of course-specific knowledge but rather by an accumulation of human or social capital: students with access to more persistent peers may acquire more skills or build a network from which they benefit in current and future courses. We show that students randomly assigned to persistent peers are more likely to build a social network of persistent students, which may explain improvements in contemporaneous performance. If these social networks persist and students become friends with more persistent peers, this could also contribute to explaining the longer-run impacts of peer personality on performance.

The evidence on externalities arising from peer personality on educational outcomes is scarce. Most of the existing studies on peer effects in education focus on how various measures of peer achievement affect performance. Papers that exploit random assignment to identify a causal effect of peer achievement include Zimmerman (2003), Whitmore (2005), Carrell, Fullerton, and West (2009), Lyle (2009), Duflo, Dupas, and Kremer (2011), Carrell, Sacerdote, and West (2013), De Giorgi and Pellizzari (2013), and Booij, Leuven, and Oosterbeek (2017). Feld and Zölitz (2017) study achievement peer effects in the same setting as our present paper. ${ }^{4}$ Prominent papers studying the effects of peer race and gender include Hoxby (2000), Angrist and Lang (2004), Hoxby and Weingarth (2005), Lavy and Schlosser (2011), and Oosterbeek and van Ewijk (2014).

\footnotetext{
1 Note that although Feld and Zölitz (2017) use data from the same institution, their estimation sample does not overlap with ours. Feld and Zölitz (2017) use administrative data from 2009-11. In contrast, we combine administrative data from 2012-16 with personality data we collected using surveys among all incoming students in these five years.
} 
Only a few papers have touched upon the effect of peer characteristics related to personality. Figlio (2007) shows that boys with female-sounding names, who are generally more likely to display behavioral problems, negatively affect their peers' test scores. Carrell and Hoekstra (2010) show that children who experienced domestic violence negatively affect their peers' reading and math test scores. Carrell, Hoekstra, and Kuka (2018) follow up on these results and show that exposure to disruptive peers in elementary school reduces earnings at the age of 26 by $3 \%-4 \%$. While none of these papers explicitly study the role of peer personality, their findings suggest that personality traits that underlie students' disruptive behavior negatively affect their classroom peers.

The only paper to explicitly consider the association between peer personality and educational outcomes is by Shure (2017), who investigates the relationship between peer personality and grades in secondary school. To identify peer effects, she exploits idiosyncratic variation in peer personality in a school fixed effects framework. Consistent with our results, Shure (2017) documents a positive relationship between peer conscientiousness and student performance. Moreover, she finds a negative association between performance and peer extraversion. The key difference between Shure (2017) and our study lies in the empirical strategy: while Shure (2017) relies on school fixed effects, we exploit the random assignment of students into teaching sections. Our approach alleviates concerns related to nonrandom student sorting into peer groups.

Our paper establishes a novel connection between the peer effects literature and a growing body of evidence documenting the importance of individuals' personality traits. We make two contributions to these two strands of literature. First, by studying the role of peer personality instead of achievement, gender, or race, we focus on a novel facet of peer effects in human interaction. Second, we provide the first causal evidence that personality traits of people around us affect human capital accumulation.

Our key finding that peer personality affects performance has important implications for the social returns of interventions that affect socioemotional skills. For instance, the social returns of interventions such as the Perry Preschool Project, which enhance socioemotional skills, will be underestimated if spillovers driven by peer personality are neglected. Such spillovers may arise, for instance, if children affected by the intervention in turn affect their siblings, friends, neighbors, or classmates.

The remainder of the paper is structured as follows. Section II describes the institutional environment and the assignment procedure of students to sections. Section III describes the data set. Section IV discusses the empirical strategy and shows evidence that section assignment is random. Section V reports results. Section VI investigates underlying channels. Section VII concludes. 


\section{Institutional Background}

We collected the data from a business school in the Netherlands. ${ }^{5}$ At present, about 4,300 students are enrolled in bachelor's, master's, and PhD programs at this institution. In contrast to the US college system, all students who enroll at the business school are committed to studying a specific program from the first year onward. In all bachelor's programs, students must take eight compulsory courses and two shorter skills courses in the first year. Some of those courses are program specific. In the second and third years, students choose a major and elective courses. In this paper, we concentrate on performance in the first year, when all students in a given study program take a set of compulsory courses and take centrally organized and mostly machine-graded exams.

The academic year at the business school is divided into four regular teaching periods of 2 months each and two 2-week skills periods. Students usually take two courses simultaneously in each regular period and one course in each skills period. In our analysis, we focus on the courses taken during the regular teaching periods because skills courses are typically not graded or the relevant peer group cannot be identified. ${ }^{6}$

Importantly, the bulk of teaching at the business school occurs in sections. Sections are small groups of up to 16 students and are taught by one instructor. This peer group will be the focus of our analysis. Students typically meet twice per week for 2 hours with their section peer group to discuss the course material. In this discussion-based approach, students generate questions about a topic, try to answer these questions in selfstudy, and then discuss their findings with their peers in the next session. The role of the instructor in this discussion-based system is to monitor and guide the classroom discussion. In most courses, students solve problem sets and read course materials at home and then meet to discuss the material and solutions to the problem sets. For each course, students are required to attend the majority of section meetings. Additionally, most courses have lectures that students of all sections attend.

To assess the external validity of our findings, it is important to know how prevalent small-group teaching is. Feld, Salamanca, and Zölitz (2020) shed light on this question by collecting information on the prevalence of small-group teaching, using a survey of 69 economics and business university departments in 31 OECD (Organisation for Economic Co-operation and Development) countries. The results of this survey show that the majority $-63 \%$ of OECD universities use small-group teaching. At $66 \%$ of

\footnotetext{
${ }^{5}$ For similar but more detailed information on the institutional environment, see Feld, Salamanca, and Hamermesh (2016), Feld and Zölitz (2017), and Feld, Salamanca, and Zölitz (2020).

${ }^{6}$ In almost all skills courses, students are scheduled in different sections but end up sitting together in the same room. Furthermore, some skills courses have only a "pass" or a "fail" grade.
} 
those universities, students discuss course material and exercise solutions in small-group meetings. Small-group meetings make up around $30 \%$ of students' contact hours, and the average group size is 16.3 students. In our sample, the average group size is similar, containing 12.9 students per section. These results show that many OECD universities also use smallgroup teaching, which supports the external validity of our results.

Assignment of students to sections. - The Scheduling Department of the business school assigns students to sections and teachers to sections and allocates sections to time slots and rooms. The department uses a computer program that randomly allocates all registered students for a given course into sections. Undergraduate students are further stratified by nationality. ${ }^{7}$ After students are assigned to sections, teachers are assigned to sections, and then sections are assigned to available time slots and rooms. ${ }^{8}$ After this assignment, the scheduling program indicates scheduling conflicts. ${ }^{9}$ These conflicts arise for about $5 \%$ of the initial assignments. If the computer program indicates a scheduling conflict, the scheduler manually moves students between different sections until all scheduling conflicts are resolved. After this, the section and teacher assignments are published.

Schedulers have little interaction with students and therefore do not know them personally. They schedule thousands of students every 8 weeks and do not have time to pay special attention to individual students. The scheduling program does not show students' previous grades, gender, or personality traits. Schedulers follow the random allocation mechanism that the scheduling software suggests and ensure only that the two main nationalities (Dutch and German) are somewhat evenly distributed over teaching sections. Students do not interfere with the scheduling process.

\footnotetext{
7 This was introduced in the academic year 2010/11. The stratification occurs as follows. The scheduler first selects all German students (who are not ordered by any observable characteristic) and then uses the option "Allocate Students set SPREAD," which assigns an equal number of German students to all sections. Subsequently, the scheduler repeats this process with the Dutch students and finally distributes the students of all other nationalities into the remaining spots. Until the academic year $2013 / 14$, about $10 \%$ of the slots in each section were initially left empty and were filled with students who registered late. This procedure balanced the number of late-registration students over the sections. Since $2013 / 14$, the institution no longer admits students to courses after the registration deadline. Starting with the academic year 2013/14, students are automatically registered for first-year bachelor's courses.

${ }^{8}$ About $10 \%$ of teachers indicate time slots when they are not available for teaching. This happens before they are scheduled and requires the signature of the department chair.

9 There are three reasons for students' scheduling conflicts: (1) the student takes another elective course at the same time, (2) the student is also working as a teaching assistant and is scheduled to teach at the same time, or (3) the student indicates nonavailability for evening education. By default, all students are recorded as available for evening sessions, but they can opt out by completing an online form. About $3 \%$ of all sessions in our sample are scheduled for an evening time slot.
} 
Formal switching between assigned sections is not possible, and section instructors are instructed not to allow informal switching.

There are a few exceptions to this general procedure, for example, when the course coordinator requests to manipulate the section composition. In our sample, this is the case for only one of the first-year courses, which we therefore remove from the estimation sample. Importantly, in the estimation sample that we use throughout this paper, neither teachers, students, nor course coordinators influence the section assignment. We formally test whether the data have the characteristics expected under random assignment in section IV.

\section{Data}

\section{A. Sample and Descriptive Statistics}

For the academic years 2012/13-2016/17, we collected data on students' personality, using online questionnaires that students were required to complete at the beginning of their introductory course in quantitative methods. This course takes place in the first period of the first academic year and is obligatory for all economics and business students at the business school. Because the survey was part of a compulsory assignment students completed for the course, virtually all students filled out the questionnaires. ${ }^{10}$ Only a handful of students who dropped out of the study program during the first weeks did not answer the survey. Our sample thus comprises five full study cohorts. ${ }^{11}$

Panel A in table 1 provides a data overview. In total, we observe 4,383 firstyear bachelor's students. ${ }^{12}$ For the 17,512 student-course registrations, we observe 16,155 student-course grades. On average, $8 \%$ drop out of a course between registration and sitting the final exam. Students who dropped out of courses are included in the analysis as peers. Therefore, the peer effects we estimate represent intention-to-treat effects. The total number of sections is 1,357 . There are 23.4 sections per course on average, and the average number of students per section is 12.90 .

${ }^{10}$ Students were informed that their responses would remain confidential and that they would be used for research purposes as well as the general improvement of education.

"The Scheduling Department of the business school provided the administrative data on all scheduled sections. The Examinations Office of the business school provided the data on student course registrations, grades, and student background characteristics.

${ }_{12}$ The academic year consists of four periods, with two courses taught each period. In our analyses, we exclude the two courses in the first course period to avoid the reflection problem (Manski 1993), as well as one course in which the instructor interfered with the randomization procedure, leaving us with five courses. The sample contains 17,512 studentcourse registrations. This implies that students take four courses on average, which is less than five courses because some students quit their studies during the first year and therefore are not registered for all five courses. The number of observations in the main analyses equals the number of student-course grades. 
TABLE 1

Estimation SAmple Summary Statistics

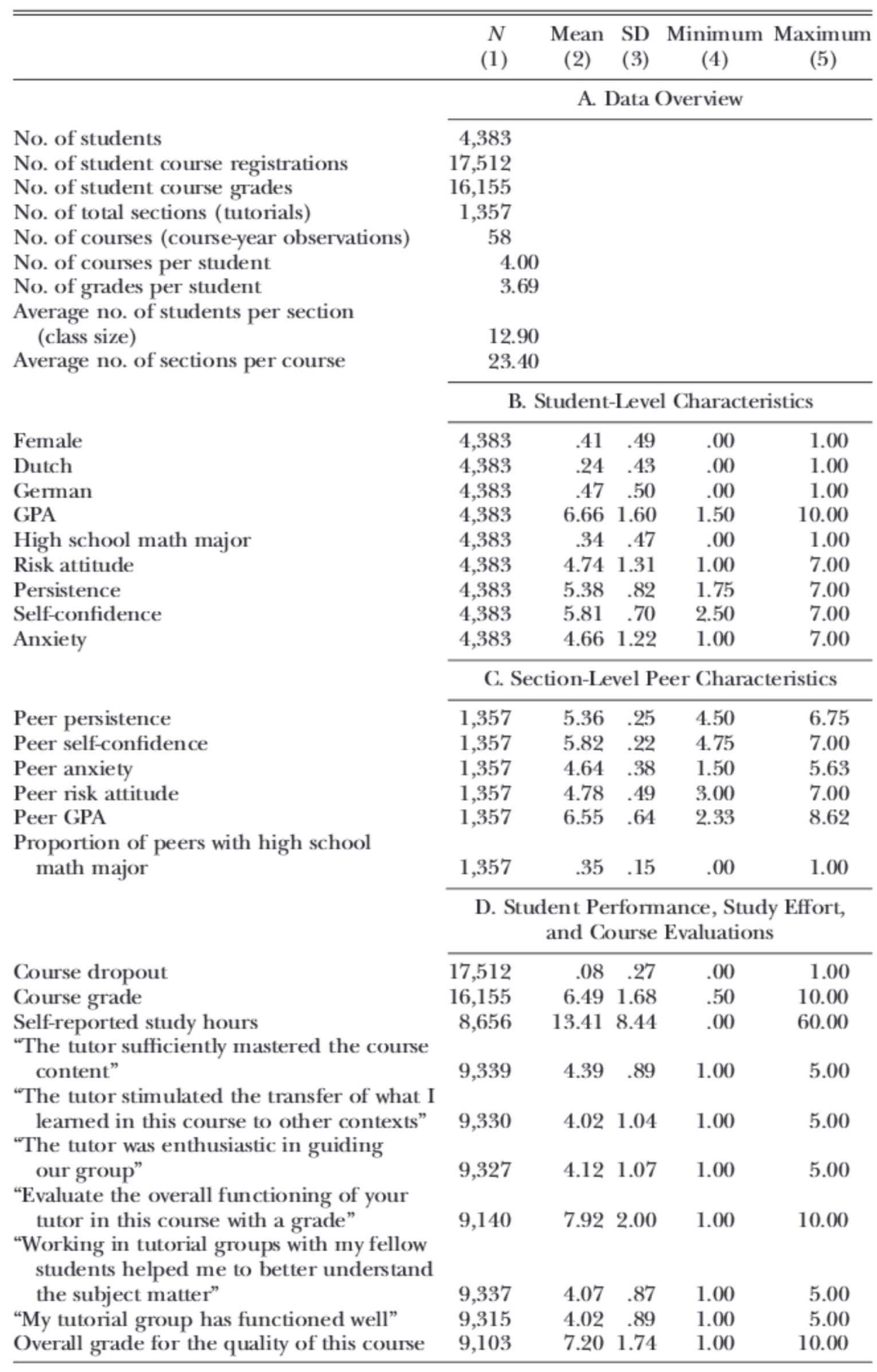


Panel B in table 1 shows student demographic characteristics and personality measures. The panel shows that around $41 \%$ of the students are female. As the business school is located close to the German border, almost $50 \%$ of the students are German, while $24 \%$ of students are Dutch. Panel B also provides summary statistics for our measures of student personality that we describe in section III.C. Panel C in table 1 summarizes the section-level peer characteristics that we construct to estimate peer effects. Figure Al shows the variation in the nonstandardized peer personality measures, and figure A2 shows the variation after netting our course-times-year fixed effects. Both figures show that there is substantial variation in peer personality - even after taking out the fixed effects that we use in our later analyses.

\section{B. Data on Student Performance and Student Course Evaluations}

The performance indicator in this study is the grade that students achieve in the centrally graded exam at the end of each course. This grade does not have a group-graded component. We use only the results of the first central exam in a course and do not take the grades of any exam retakes into consideration, as these are not comparable to the grades in the first take. Panel D in table 1 shows that the average student grade is $6.5 .^{13}$

In our analyses of mechanisms, we use survey data from online course evaluations. Panel D shows the evaluation items we analyze. Students report that they study, on average, around 13 hours per week for one course. This excludes the 6 hours per week during which they attend sections and lectures. Given that the students take two courses per period, this number of study hours is close to the 40 hours per week that full-time students are supposed to invest in their studies, according to the European Credit Transfer System framework.

The evaluation questions regarding the instructor were "The tutor sufficiently mastered the course content," "The tutor stimulated the transfer of what I learned in this course to other contexts," "The tutor was enthusiastic in guiding our group," and "Evaluate the overall functioning of your tutor in this course with a grade." The evaluation questions about peer-to-peer interaction were "Working in tutorial groups with my fellow students helped me to better understand the subject matter" and "My tutorial group has functioned well." For our analysis, we aggregate the answers to the four questions about the instructor and the answers to the two questions about peers into two indices. To construct these indices,

\footnotetext{
13 The Dutch grading scale ranges from 1 to 10 , with 5.5 usually being the lowest passing grade. If the grade of a student is lower than 5.5, the student fails the course and has the opportunity to take the exam a second and third time.
} 
we standardize the separate items, compute the average of peer- and instructor-related items, and standardize again.

\section{Measures of Student Persomality and Attitudes}

Table 2 provides an overview of the personality measures that we use. ${ }^{14}$ All measures are self-reported on a scale from 1 to 7 . We use the Student Motivation Scale, as introduced by Martin (2009), to measure persistence, self-confidence, and anxiety. Each of the traits is measured by four questions. This scale was developed specifically to measure student motivation in education. Hence, all questions are framed in the context of education.

How reliable are the measures we use, and how much do these personality measures overlap with other, more commonly used measures of personality? In appendix B, we provide evidence on the Cronbach's alphas of our personality measures. Cronbach's alphas are commonly used to determine the reliability of traits. Table B1 shows that the alphas range between 0.77 and 0.89 , which the personality psychology literature considers high (see Kline 2000). Appendix B also provides evidence that our measure of persistence is strongly correlated with conscientiousness and that it is a facet of grit (Duckworth et al. 2007). Furthermore, appendix B shows that our measure of anxiety is a facet of neuroticism.

Our measure of risk attitudes is the widely used question "In general, how willing are you to take risks?" Higher values indicate higher risk tolerance. Dohmen et al. (2011) and Vieider etal. (2015) show that this measure predicts behavior in incentivized lottery experiments and that it is correlated with risky behaviors in several domains across different cultures (see also Falk et al. 2018).

\section{Empirical Strategy and Randomization Check}

\section{A. Empirical Strategy}

Our goal in this paper is to estimate the effect of peer personality on students' performance. Throughout the paper, we define peer groups at the section level; when referring to peers, we mean students' section peers.

Before we test how peer personality affects outcomes, we investigate whether students' own personality traits predict their outcomes. We estimate the following model:

$$
\mathrm{GPA}_{i}=P_{i} \delta^{\prime}+X_{i} \theta^{\prime}+\varepsilon_{i},
$$

" Table Al shows the correlations between our personality measures. 
TABLE 2

Measurement of Student Personality

\begin{tabular}{|c|c|c|}
\hline Trait & Definition & Measurement \\
\hline Persistence & $\begin{array}{l}\text { How much students keep trying } \\
\text { to work out an answer or to } \\
\text { understand a problem even } \\
\text { when that problem is difficult } \\
\text { or challenging }\end{array}$ & $\begin{array}{l}\text { 1. "If I can't understand my university } \\
\text { work at first, I keep going over it } \\
\text { until I do"; } \\
\text { 2. "If my homework is difficult, I keep } \\
\text { working at it trying to figure it out"; } \\
\text { 3. "When I'm taught something that } \\
\text { doesn't make sense, I spend time } \\
\text { to try to understand it"; } \\
\text { 4. "I'll keep working at difficult } \\
\text { university work until I think I've } \\
\text { worked it out" }\end{array}$ \\
\hline Self-confidence & $\begin{array}{l}\text { Students' belief and confidence } \\
\text { in their ability to understand } \\
\text { or to do well in their studies }\end{array}$ & $\begin{array}{l}\text { Four items, e.g., "If I try hard, I } \\
\text { believe I can do my university } \\
\text { work well" }\end{array}$ \\
\hline Anxiety & $\begin{array}{l}\text { Feeling nervous when thinking } \\
\text { about their studies and worrying } \\
\text { about not doing well in their } \\
\text { studies }\end{array}$ & $\begin{array}{l}\text { 1. "When exams and assignments } \\
\text { are coming up, I worry a lot"; } \\
\text { 2. "I worry about failing exams } \\
\text { and assignments"; } \\
\text { 3. "When I do tests or exams I don't } \\
\text { feel very well"; } \\
\text { 4. "In terms of my university work, I'd } \\
\text { call myself a worrier" }\end{array}$ \\
\hline Risk attitude & Willingness to take risks & $\begin{array}{l}\text { "In general, how willing are you to } \\
\text { take risks?" }\end{array}$ \\
\hline
\end{tabular}

Note.-All concepts are measured on a scale of 1-7. Persistence, self-confidence, and anxiety were taken from the Student Motivation Scale (Martin 2009). The items for selfconfidence are not publicly available. The persistence and anxiety items have been made publicly available in Martin (2011). For a discussion and validation of the measure of risk attitude, see Dohmen et al. (2011).

where $\mathrm{GPA}_{i}$ is the GPA of student $i$ at the end of the first study year. The vector of personality traits $P_{i}$ includes the student's persistence, selfconfidence, anxiety, and risk attitude. The effect of these traits on student performance is captured by the vector $\delta^{\prime} ; X_{i}$ is a vector of control variables that includes student gender, nationality, and year-times-study-program fixed effects.

To test how peer personality affects student performance, we estimate the following model:

$$
A_{i c g}=\overline{\mathrm{PP}}_{g-i} \alpha^{\prime}+P_{i} \beta^{\prime}+X_{i} \gamma^{\prime}+\rho_{i c}+u_{i g g},
$$

where $A_{i g}$ is the grade of student $i$ in course $c$ in section $g$. The vector $\overline{\mathrm{PP}}_{g-i}$ refers to the mean personality traits of all students in section $g$ excluding student $i$, that is, the leave-out mean. We control for several variables to enhance the precision of our estimates: students' own personality measures and a vector of other control variables $X_{i}$ that includes 
students' own gender and nationality, their GPA at the start of the course, and indicators for scheduling conflicts. We include the latter to account for potential nonrandom assignment due to scheduling conflicts. The term $\rho_{i c}$ denotes course-year fixed effects, and $u_{i g}$ is the error term. We cluster standard errors at the level of randomization, which is at the course level in our case. ${ }^{15}$

Personality traits are correlated with GPA. Therefore, one obvious question is whether $\alpha^{\prime}$ in equation (2) is indeed identifying the true effect of peer personality on student performance or whether $\alpha^{\prime}$ is picking up an underlying achievement peer effect. To assess to what degree this is the case, we also estimate an extended version of this model in which we control for other peer characteristics, such as GPA, gender, and nationality, to disentangle the impact of peer personality from these characteristics. ${ }^{16}$ To investigate heterogeneous treatment effects, we also estimate a variant of equation (2) where we allow $\alpha^{\prime}$ to vary by students' own level of the respective trait.

In a further robustness check, we include peers' entry test scores for math and statistics. The difference in the peer personality coefficients in the model with and without these controls provides information on the extent to which these observables affect the relationship between peer personality and performance. If the estimates remain robust to the inclusion of these observables, it is likely that they also remain robust to factors not included in the estimations (see Altonji, Elder, and Taber 2005).

Feld and Zölitz (2017) have shown that classical measurement error in the peer characteristics of interest can lead to substantial overestimation of peer effects when group assignment is nonrandom. When group assignment is random - as is the case in our setting - classical measurement error will attenuate peer effects estimates, that is, bias them toward zero. Because peer personality is arguably measured with a substantial amount of error, we expect that our estimates of $\alpha^{\prime}$ will be significantly attenuated. This implies that we identify lower bounds and that the true underlying effect is likely to be larger than our estimates.

To simplify the interpretation of our estimates, we standardize own and peer personality measures, as well as course grades, to have a mean of zero and unit variance.

${ }_{5}$ The results do not change when we cluster at the section level (see table A6).

${ }^{16}$ Peer GPA is defined as the running average of grades obtained in all previous courses. This implies that whenever we include GPA in an estimation, we refer to a pretreatment characteristic that was fixed before the randomization into sections that takes places before the start of each new course. Peer GPA therefore cannot be affected by students' own characteristics. 


\section{B. Tests for Random Assignment}

The key identifying assumption of this paper is that the assignment of students to sections (i.e., peer groups) is random. The scheduling procedure described in section III ensures that student assignment to sections is random, conditional on scheduling conflicts. Using data from the same environment, Feld and Zölitz (2017) have shown that section assignment has the properties that one would expect under random assignment. To confirm this result with respect to the sample we study in this paper and with respect to peer personality, we test whether student personality relates to average peer personality in the assigned section. This randomization check closely follows Guryan, Kroft, and Notowidigdo (2009) and controls for the course-level leave-out mean of the respective characteristics to account for the mechanical relationship between ownand peer-level variables. Table 3 reports the results of this analysis and

TABLE 3

TeST FOR RANDOM ASSIgNMENT

\begin{tabular}{|c|c|c|c|c|c|}
\hline & $\begin{array}{c}\text { Peer } \\
\text { Persistence } \\
\text { (1) }\end{array}$ & $\begin{array}{c}\text { Peer } \\
\text { Self-Confidence } \\
(2)\end{array}$ & $\begin{array}{c}\text { Peer } \\
\text { Anxiety } \\
(3)\end{array}$ & $\begin{array}{l}\text { Peer Risk } \\
\text { Attitude } \\
\quad(4)\end{array}$ & $\begin{array}{c}\text { Proportion } \\
\text { of Peers with } \\
\text { High School } \\
\text { Math Major } \\
\text { (5) }\end{array}$ \\
\hline Persistence & $\begin{array}{l}.0108 \\
(.015) \\
{[.470]}\end{array}$ & & & & \\
\hline Self-confidence & & $\begin{array}{l}.0088 \\
(.009) \\
{[.309]}\end{array}$ & & & \\
\hline Anxiety & & & $\begin{array}{c}-.0149 \\
(.011) \\
{[.190]}\end{array}$ & & \\
\hline Risk attitude & & & & $\begin{array}{l}.0034 \\
(.010) \\
{[.729]}\end{array}$ & \\
\hline $\begin{array}{l}\text { High school } \\
\text { math major }\end{array}$ & & & & & $\begin{array}{l}.0004 \\
(.003) \\
{[.913]}\end{array}$ \\
\hline Observations & 17,512 & 17,512 & 17,512 & 17,512 & 17,512 \\
\hline$R^{2}$ & .169 & .136 & .242 & .450 & .180 \\
\hline
\end{tabular}

Note. - The dependent variable in all columns is the standardized section-level leaveout mean of the respective personality characteristic, i.e., the average peer persistence in a section excluding the student's own personality. All models are estimated with ordinary least squares regressions that include course-times-year fixed effects and controls for gender and nationality (Dutch, German). Following the Guryan, Kroft, and Notowidigdo (2009) correction method, we control for the course-level leave-out mean in all estimations. Robust standard errors clustered at the course level are in parentheses; $p$-values are reported in brackets. 
shows that peer personality is not systematically related to students' own personality. All coefficients are small and not statistically significant, which confirms that the section assignment is random. ${ }^{17}$

\section{Simultaneity Problem}

A potential threat to identification of personality peer effects occurs when personality and academic performance are measured simultaneously. Simultaneous measurement may induce a correlation between peer personality and performance, as students could influence each other's assessments and face the same shocks. This may lead to bias in the estimation of peer effects. In our data, this could occur in the first course period at university, but not in later periods because students are randomly reassigned to a new section of peers in each of these periods. By excluding the first course period from our estimation sample, we ensure that our estimates are not affected by the simultaneity problem.

\section{Results}

A. The Relationship between Students' Own Personality and Performance

Are personality traits relevant predictors of students' own performance? We investigate this question by looking at how students' own personality traits, as measured at the beginning of the first study year, relate to student GPA at the end of their first year in university. Table 4 shows that all personality traits that we measure are significantly correlated with GPA. A 1 standard deviation increase in persistence is correlated with a 0.13 standard deviations higher GPA. Self-confidence is also positively related to GPA, with a similar magnitude. We further find that anxiety is negatively related to GPA. A 1 standard deviation increase in anxiety is associated with a 0.16 standard deviations reduction in GPA. We also find that students who are more risk tolerant have a lower GPA. A 1 standard deviation increase in risk tolerance is related to a 0.09 standard deviations decrease in GPA. For reference purposes, we also estimate a regression of GPA on a dummy variable that equals one if a student has a high school math major, in column 5 . In column 6 , we include all personality

\footnotetext{
${ }^{17}$ The number of observations in the randomization check differs from the number of observations in the main analyses because some students drop out of the courses. Table A2 provides balancing tests for the sample of students who did not drop out and shows that students' pretreatment characteristics are also unrelated to peer personality when we condition on this subsample. Table A3 shows that peer personality does not affect the probability of dropping out of a course, which implies that there is no selective attrition.
} 
TABLE 4

Student Personality and Student Achievement

\begin{tabular}{|c|c|c|c|c|c|c|}
\hline & (1) & (2) & (3) & (4) & (5) & (6) \\
\hline Persistence & $\begin{array}{l}.1307 \\
(.015) \\
{[.000]}\end{array}$ & & & & & $\begin{array}{l}.1058 \\
(.017) \\
{[.000]}\end{array}$ \\
\hline Self-confidence & & $\begin{array}{c}.1005 \\
(.014) \\
{[.000]}\end{array}$ & & & & $\begin{array}{c}.0354 \\
(.016) \\
{[.027]}\end{array}$ \\
\hline Anxiety & & & $\begin{array}{c}-.1558 \\
(.015) \\
{[.000]}\end{array}$ & & & $\begin{array}{r}-.1427 \\
(.015) \\
{[.000]}\end{array}$ \\
\hline Risk attitude & & & & $\begin{array}{c}-.0926 \\
(.015) \\
{[.000]}\end{array}$ & & $\begin{array}{r}-.1098 \\
(.015) \\
{[.000]}\end{array}$ \\
\hline High school math major & & & & & $\begin{array}{c}.2524 \\
(.031) \\
{[.000]}\end{array}$ & $\begin{array}{l}.2159 \\
(.030) \\
{[.000]}\end{array}$ \\
\hline Observations & 4,383 & 4,383 & 4,383 & 4,383 & 4,383 & 4,383 \\
\hline$R^{2}$ & .092 & .086 & .098 & .084 & .090 & .134 \\
\hline
\end{tabular}

NoTE.- This table shows student-level regressions with one observation representing one individual. The dependent variable in all columns is the end-of-first-year standardized GPA based on all first-year courses. All models are estimated with ordinary least squares regressions that include cohort-times-study-program fixed effects and that control for gender and nationality (Dutch, German). Robust standard errors are in parentheses; $p$-values are reported in brackets.

measures in one model. While the magnitudes of the estimated coefficients change by some degree, they remain highly statistically significant and do not change sign.

Figure 1 provides an illustration of these relationships. The plots in figure 1 visualize the regression results reported in column 6 of table 4 . The construction of these binned scatter plots follows Chetty, Friedman, and Rockoff (2014). We first regress course grades on the set of controls included in column 6 of table 4 to obtain the residualized course grades. Next, we rank-order observations by our measures of personality and split them into equally sized bins. Subsequently, we plot the mean of the residualized course grades within each bin against the normalized mean value of personality in that bin. Figure 1 shows that the relationships found in table 4 are linear.

Taken together, the results in table 4 and figure 1 show that students' own personality traits are relevant predictors of study success. Our findings are broadly consistent with previous work on the relationship between educational attainment and personality (see Borghans et al. 2008, 2016 for reviews). ${ }^{18}$

${ }^{18}$ Borghans et al. (2008) show, in their overview of the literature, that conscientiousness, which is related to our measure of persistence, is by far the best predictor of grades among the personality traits $(r=.22)$, and that, after openness to experience, it is the best predictor of years of education $(r=.11)$. 

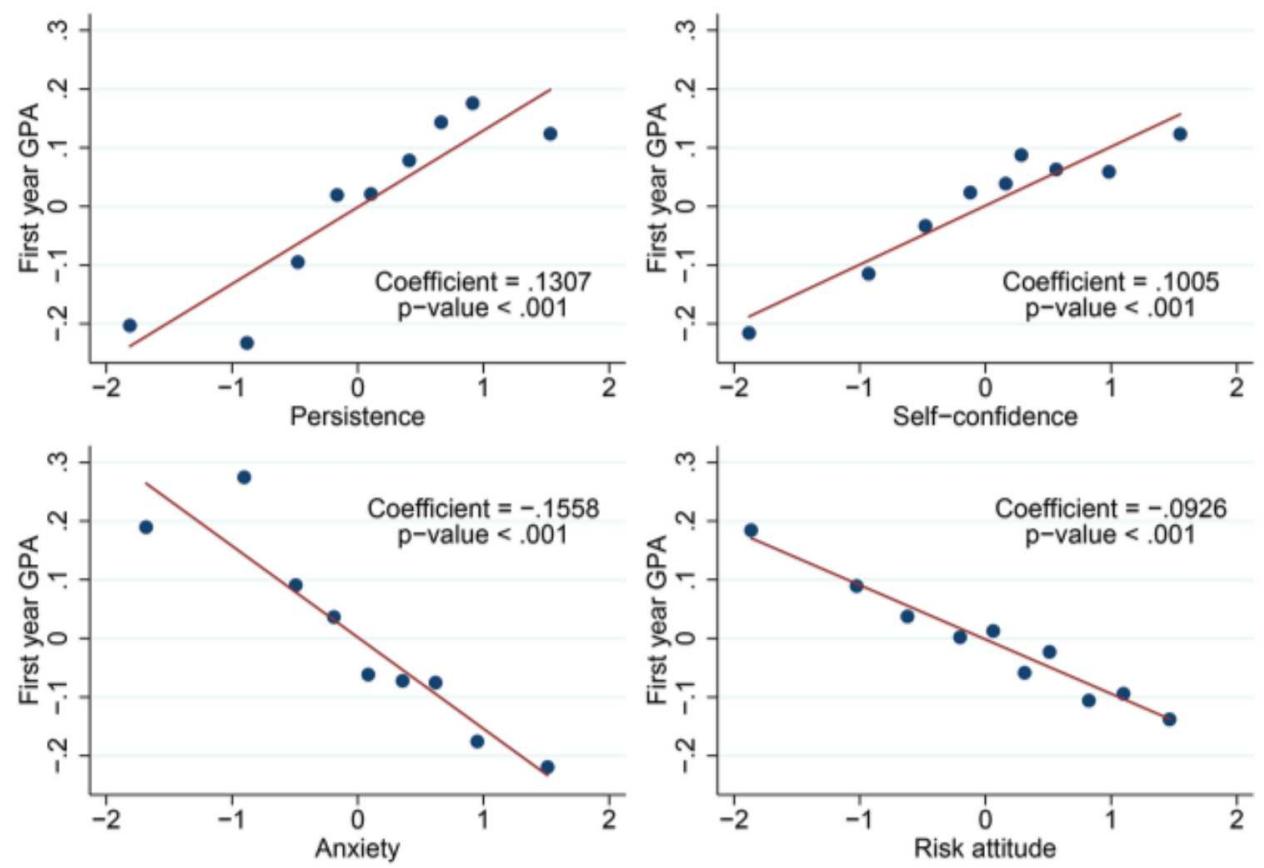

FIG. 1.-Student personality and performance. These plots visualize the regression results reported in column 6 of table 4 . The construction of these binned scatter plots follows Chetty, Friedman, and Rockoff (2014). We first regress course grades on the set of controls included in column 6 of table 4 to obtain the residualized course grades. Next, we rankorder our measures of personality and split them into equally sized bins. We then plot the mean of the residualized course grades within each bin against the normalized mean value of personality in that bin. $N=4,383$.

\section{B. The Impact of Peer Personality on Performance}

Before analyzing the effect of peer personality on grades, it is important to test whether peer personality affects first-year course dropout. The estimation results, reported in table A3, show that this is not the case. Column 7 shows that the probability of dropping out of the courses, which determines whether we observe students' grades, is independent of peer personality.

Table 5 displays the estimation results of our main analysis on how peer personality affects students' grades. We find that students who were randomly assigned to more persistent peers obtain higher exam grades. A 1 standard deviation increase in peer persistence raises performance by $1.9 \%$ of a standard deviation. We also find that exposure to risk-tolerant peers negatively affects grades. A 1 standard deviation increase in peers' risk tolerance lowers grades by $1.1 \%$ of a standard deviation. We do not find that peers' self-confidence or anxiety are significantly related to grades.

As our measures of peer personality might be collinear to some degree, we include all peer personality variables in one model in column 5 of 
TABLE 5

Effect of Peer Personality on Student Performance

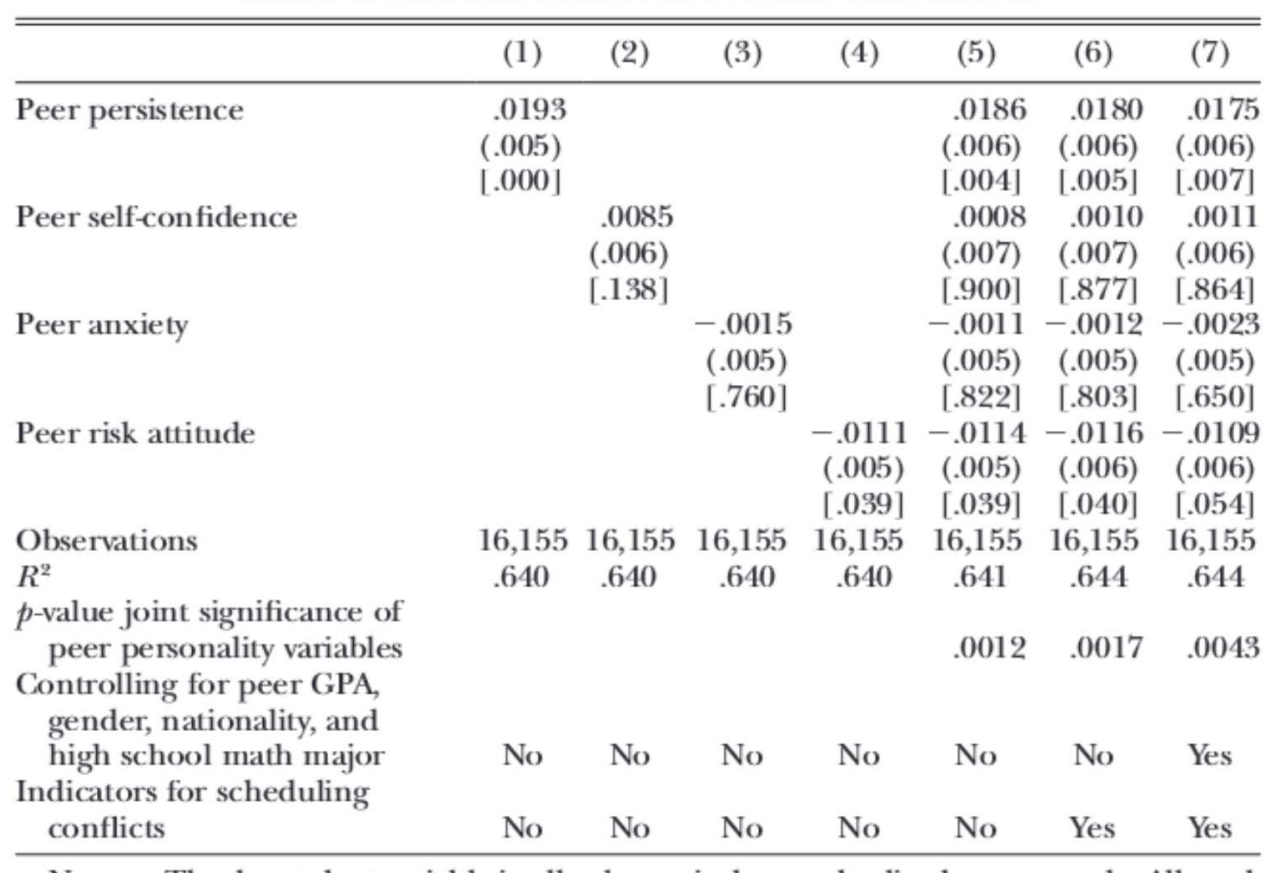

NoTE. - The dependent variable in all columns is the standardized course grade. All models are estimated with ordinary least squares regressions that include measures for the respective own personality trait as well as measures for the respective own personality trait and gender, nationality (Dutch, German), third-order polynomial in GPA, course-times-year fixed effects, class size, and the number of students with nonmissing personality measures. The estimation sample of this table consists of all student-course observations with nonmissing grades. Table A2 shows the randomization check for this estimation sample. The number of observations is lower than in table 3 because some students drop out of the course. Table A3 s hows that peer personality does notaffect dropout. Robust standard errors clustered at the course level are in parentheses; $p$-values are reported in brackets.

table 5. Importantly, the point estimates remain similar when we include all peer personality measures at once instead of estimating models with one peer characteristic at a time. This suggests that our measures of peer personality capture distinct components of students' personality traits. In column 6 , we additionally include fixed effects for scheduling conflicts. The estimated coefficients remain virtually unchanged when we include these fixed effects.

In column 7 of table 5, we additionally include other observable peer characteristics as control variables. In particular, we include peer GPA, the proportion of female peers, and the proportion of Dutch and German peers, as well as the percentage of peers who have a high school math major. If peer personality affects performance mainly through these peer characteristics, we would expect that their inclusion reduces the effect size of the peer personality coefficients. Column 7 shows that this is not the case and that the point estimates remain almost unchanged when we control for other peer observables. In the spirit of Altonji, Elder, and Taber 
(2005), this result suggests that omitted-variable bias plays a limited role in our estimations.

To investigate whether measurement error in peer achievement (GPA) may confound the estimates of peer personality, we control for multiple other measures of peer achievement assessed when students enter the business school, including whether they selected a math major in high school and their math and statistics entry test scores. Table A4 shows that the results remain similar when we include these measures next to peer GPA in the regression. We conclude that it is unlikely that measurement error in peer GPA is confounding the effect of peer personality on grades found in this paper.

In table 5 , we estimate peer effects for four different personality traits. This implies that some statistically significant effects might simply represent chance findings. We address this concern by (1) performing an $F$-test for joint significance of all peer personality characteristics and (2) testing which estimates remain significant after correction for multiple-hypothesis testing. Table 5 shows that we can clearly reject that performance is independent of peer personality. The $p$-value for the test of joint significance in our most conservative specification in column 7 is .0043. Table A5 further shows that the effect of peer persistence remains statistically significant when we use the Bonferroni correction or other commonly used correction methods for multiple-hypothesis testing. The effect of peer risk attitude, however, is no longer statistically significant when we correct for multiple-hypothesis testing.

In our analyses, we have 58 clusters, that is, course-times-year observations. A potential threat to statistical inference is that this number of clusters is relatively small. To address this concern, we use the method developed by Donald and Lang (2007), which is a two-step estimator that adjusts standard errors for a small number of clusters. By doing so, we essentially recognize that the fundamental unit of observation is a cluster and not an individual within a cluster. The results reveal that none of our findings change in a qualitative sense when $p$-values are corrected for the small number of clusters. Likewise, the conclusions do not change when we cluster on the section level (see table A6).

Taken together, the point estimates presented in table 5 show that peer persistence has a robust causal impact on student achievement and that personality peer effects are distinct from the effects of peer achievement, gender, or country of origin. Figure 2 visualizes these findings and shows that the effects of peer persistence and peer risk tolerance on performance are fairly linear over the range of available support.

How does the size of the peer persistence effect we find compare to the effects of other peer characteristics and the impact of instructors in the same setting? When we compare our effect to achievement peer effects, we find that the impact of a 1 standard deviation increase in peer persistence 

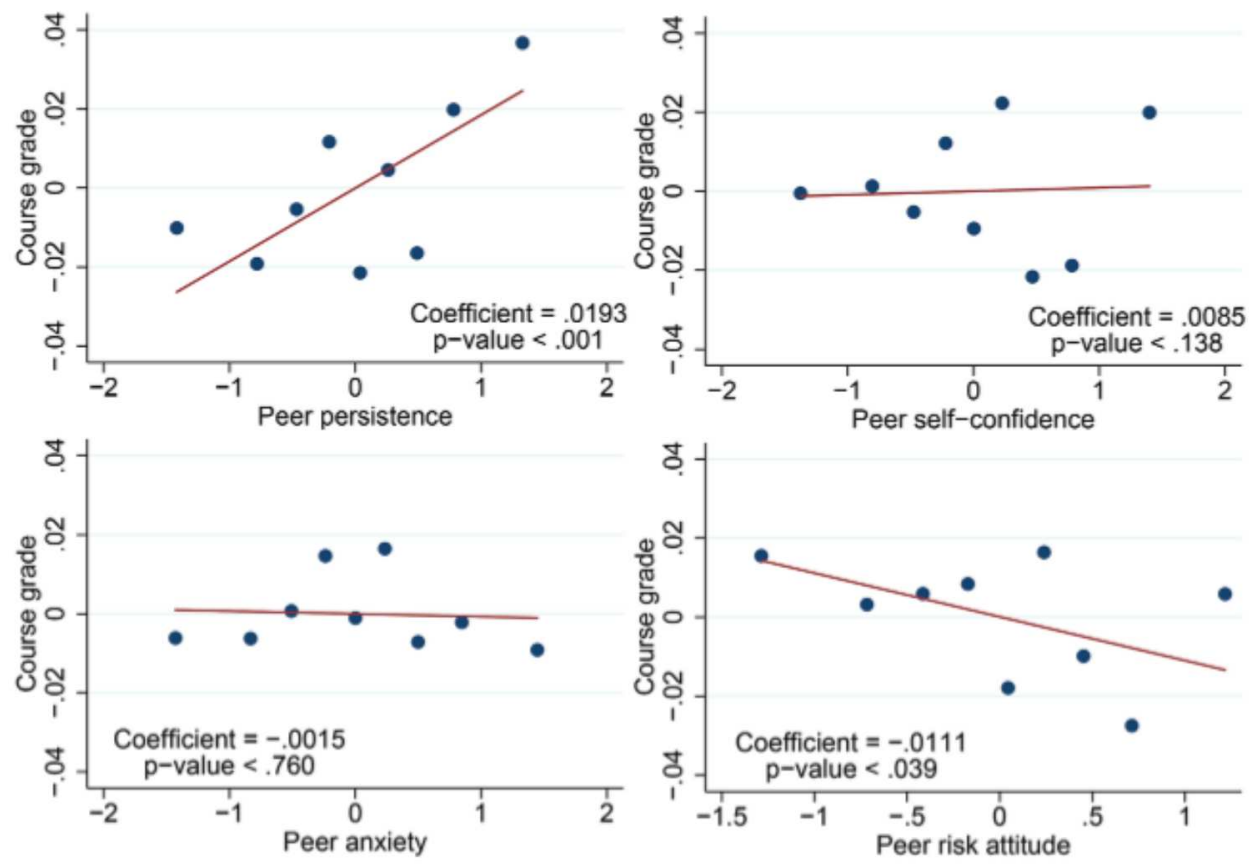

FIG. 2.-Impact of peer personality on performance. These plots visualize the regression results reported in column 7 of table 5 . The construction of these binned scatter plots follows Chetty, Friedman, and Rockoff (2014). We first regress course grades on the set of controls included in column 7 of table 5 to obtain the residualized course grades. Next, we rank-order our measures of peer personality and split them into equally sized bins. We then plot the mean of the residualized course grades within each bin against the normalized mean value of peer personality in that bin. $N=16,155$.

is about twice as large as the impact of a 1 standard deviation increase in peer GPA (Feld and Zölitz 2017). When compared to gender peer effects, the effect of a 1 standard deviation increase in peer persistence is about twice as large as the impact of a 10 percentage point increase in the proportion of female peers for women's grades (Zölitz and Feld 2019). Compared to rank effects, the effect of 1 standard deviation higher peer persistence is about as large as the effect of increasing students' GPA rank by 10 percentiles, that is, one position in a group of 11 students (Elsner, Isphording, and Zölitz 2018). Comparing our effect to teacher effects shows that the impact of a 1 standard deviation increase in peer persistence is approximately the same size as that of being taught by a 1 standard deviation better teacher, as captured by teacher value added (Feld, Salamanca, and Zölitz 2020).

\section{Effects on Other Aspects of Performance}

Does peer persistence affect other performance aspects besides contemporaneous grades? Table 6 shows how peer personality affects other 
TABLE 6

Peer Personaltty and Overali. First-Year Performance.

\begin{tabular}{|c|c|c|c|}
\hline & $\begin{array}{l}\text { No. of First-Year } \\
\text { Courses Passed } \\
\text { (1) }\end{array}$ & $\begin{array}{c}\text { Successfully Completed } \\
\text { the First Year } \\
(2)\end{array}$ & $\begin{array}{c}\text { Standardized End- } \\
\text { of-First-Year GPA } \\
\text { (3) }\end{array}$ \\
\hline \multirow[t]{3}{*}{ Peer persistence } & .0451 & .0127 & .0239 \\
\hline & $(.024)$ & $(.007)$ & $(.011)$ \\
\hline & {$[.060]$} & {$[.067]$} & {$[.033]$} \\
\hline \multirow[t]{3}{*}{ Peer self-confidence } & .0410 & .0027 & .0040 \\
\hline & $(.023)$ & (.007) & $(.011)$ \\
\hline & {$[.075]$} & [.683] & {$[.718]$} \\
\hline \multirow[t]{3}{*}{ Peer anxiety } & .0205 & .0022 & .0044 \\
\hline & $(.024)$ & $(.007)$ & $(.011)$ \\
\hline & [.392] & {$[.752]$} & {$[.694]$} \\
\hline \multirow[t]{3}{*}{ Peer risk attitude } & -.0151 & -.0084 & -.0031 \\
\hline & $(.032)$ & $(.009)$ & $(.015)$ \\
\hline & {$[.636]$} & [.362] & {$[.836]$} \\
\hline Observations & 4,082 & 4,082 & 3,931 \\
\hline$R^{2}$ & .509 & .450 & .723 \\
\hline \multicolumn{4}{|l|}{$p$-value joint } \\
\hline personality variables & .0159 & .2062 & .1803 \\
\hline \multicolumn{4}{|l|}{ Mean dependent } \\
\hline variable & 2.8 out of 6 & .4829 & 0 \\
\hline \multicolumn{4}{|l|}{ Program-times-year } \\
\hline fixed effects & Yes & Yes & Yes \\
\hline
\end{tabular}

NotE. This table shows student-level regressions in which one observation represents one individual. The dependent variable in col. 1 is the total number of courses that a student passed during the first study year. The dependent variable in col. 2 is an indicator for whether a student successfully completed the first year based on the institution's requirements. The dependent variable in col. 3 is a student's standardized GPA based on all firstyear courses. All models are estimated with ordinary least squares regressions that include program-year fixed effects, measures for the respective own personality traits and own characteristics such as gender, nationality (Dutch and German), and the pretreatment GPA measured in the first period of the first year. In this table, the unit of observation is the student. Robust standard errors are in parentheses; $p$-values are reported in brackets.

aggregate study outcomes in the first year. In this analysis, we investigate the overall number of courses passed, successful completion of first-year requirements, and the final first-year GPA across all courses. ${ }^{19}$ Because these outcomes are invariant at the individual level, we aggregate peer personality across all peers that students meet in first-year sections. This approach reduces the underlying support and statistical power but provides us with an idea of the overall importance of all peers in the first year. Because this approach prevents us from controlling for the exact level of randomization by including course-times-year fixed effects, we instead include year-times-study-program fixed effects to account for

${ }_{19}$ Table A7 reports evidence on whether course choices are affected by peer personality. We find some suggestive evidence that having persistent peers makes students choose less mathematically oriented electives in the second and third years. However, we cannot draw strong conclusions because the effect is small and marginally significant at the $10 \%$ level. 
differences in the pool of peers. Table 6 shows that peers across all sections of the first year have a meaningful impact on the number of courses passed, the probability of passing the first year, and the GPA at the end of the first year. Column 1 shows that exposure to more persistent and selfconfident peers raises the course passing rate. Column 2 shows that students with more persistent peers are also more likely to meet the study requirements for successfully completing the first year. ${ }^{20}$ The effect, however, is very small and only marginally significant. A 1 standard deviation increase in peer persistence raises the probability of successfully completing the first year by 1.3 percentage points. Column 3 shows that having more persistent peers also raises the GPA of all courses in the first year. A 1 standard deviation increase in persistence of all peers raises the overall GPA by $2.4 \%$ of a standard deviation.

\section{Mechanisms}

Why does the personality of peers affect students' grades? In this section, we analyze the effects of peer personality on students' self-reported study hours and students' evaluations of the course and the teacher. We also investigate the interaction between peer personality and measures of teacher quality, and whether performance in parallel and subsequent courses is affected. Moreover, we analyze whether peer personality affects social networks that emerge at the start of students' bachelor studies.

\section{A. Self-Reported Study Hours}

Peer personality might affect student grades if students start working harder and studying for more hours when they work with persistent peers. Using individual-level data from students' course evaluations, we can shed light on this potential explanation. At the end of each period, before learning their grade, students complete an online course evaluation. In these evaluations, students report their average weekly course study hours and evaluate their peer-to-peer interactions, the instructor, and overall course quality. $^{21}$

\footnotetext{
20 Students enrolled in any study program are required to have obtained at least 47 credits ( 34 credits before 2015 ) within the first-year bachelor's courses to be eligible for admission to the final bachelor's exam program. At least 6.5 credits of these 47 credits must be obtained within the "Quantitative Methods 1" or "Quantitative Methods 2" courses. Exemptions from these requirements can be granted for medical reasons. First-year completion requirements differ across years and study programs but typically require passing one or both statistics courses and between two and four additional courses.

${ }^{21}$ Participation in the questionnaire is voluntary, and not all students complete the course evaluation forms. Table A8 shows that peer personality does not affect students' probability of responding to the student course evaluation survey. Table A9 replicates our main analysis for the subsample of students taking part in the course evaluations and shows that point estimates for this subsample and the full sample are very similar.
} 
Table 7 shows estimates for the effects of peer personality on study hours. ${ }^{22}$ Column 1 shows that peer persistence does not significantly affect self-reported study hours. The effect is small and precisely estimated. This suggests that increased study hours do not drive the effect of peer persistence on grades. Because study hours may not accurately capture study effort, it remains possible, however, that exposure to persistent peers raises students' study effectiveness. Our analysis of average study hours therefore does not rule out that exposure to more persistent peers makes students become more efficient learners.

\section{B. Teachers}

Peer personality might affect student grades if more persistent peers motivate teachers to provide better or more tailored instructions. Table 7 provides an indirect test for this mechanism: we test whether peer persistence affects how students perceive the teacher in their teaching evaluations. Column 2 shows that peer persistence does not affect how students evaluate their instructors.

Another mechanism for how peer personality affects grades could be that students with certain personality traits interact more with each other or make the course more attractive for other students. The results in columns 3 and 4 show, however, that peer persistence is also not related to perceptions of group functioning or the overall course quality.

Instead of relying on course evaluations as proxies for teacher quality, one could also use teacher value-added measures. While we can compute value-added measures based on students' grades, we cannot directly test whether peer personality affects teachers' performance captured by valueadded measures. If we used residualized grades to estimate teacher productivity with teacher value-added models, we would falsely attribute the contribution of persistent peers to the teacher and therefore falsely conclude that teachers who teach persistent students have a high value added. Directly estimating whether persistent peers leads to higher teacher value added would thus provide biased estimates and is therefore not a feasible solution.

What we can do is analyze whether the effects of peer personality are moderated by teacher productivity. To construct teacher value added, we

\footnotetext{
2 Our measure of study hours is self-reported, which implies that it may not accurately measure study effort. To investigate what exactly study hours measure, we analyze the relationship between own personality traits and own study hours. Table A10 shows that own personality traits predict own study hours. For example, a 1 standard deviation increase in persistence is related to 1.5 hours more self-reported study time. We find positive effects for anxiety, while self-confidence and risk tolerance are negatively related to study hours. Taken together, the evidence in table A10 shows that our measure of study hours is systematically correlated with personality.
} 
TABLE 7

Mecilninisms I: Student Course Evaluntions

\begin{tabular}{|c|c|c|c|c|}
\hline & $\begin{array}{l}\text { Study } \\
\text { Hours } \\
\text { (1) }\end{array}$ & $\begin{array}{c}\text { Instructor } \\
\text { Quality Index } \\
\text { (2) }\end{array}$ & $\begin{array}{l}\text { Peer Interaction } \\
\text { Index } \\
(3)\end{array}$ & $\begin{array}{c}\text { Overall } \\
\text { Course Quality } \\
\text { (4) }\end{array}$ \\
\hline \multirow[t]{3}{*}{ Peer persistence } & .0238 & -.0166 & -.0066 & -.0020 \\
\hline & $(.111)$ & $(.022)$ & $(.018)$ & $(.017)$ \\
\hline & {$[.832]$} & {$[.452]$} & {$[.709]$} & {$[.907]$} \\
\hline \multirow{3}{*}{ Peer self-confidence } & .0186 & -.0053 & -.0029 & -.0172 \\
\hline & $(.103)$ & $(.025)$ & $(.018)$ & $(.017)$ \\
\hline & {$[.857]$} & {$[.834]$} & {$[.877]$} & {$[.317]$} \\
\hline \multirow[t]{3}{*}{ Peer anxiety } & .1566 & -.0566 & -.0296 & -.0605 \\
\hline & $(.116)$ & $(.018)$ & $(.016)$ & $(.016)$ \\
\hline & {$[.180]$} & {$[.002]$} & {$[.074]$} & {$[.000]$} \\
\hline \multirow[t]{3}{*}{ Peer risk attitude } & -.0893 & .0026 & .0098 & .0044 \\
\hline & $(.107)$ & $(.022)$ & $(.021)$ & $(.019)$ \\
\hline & {$[.408]$} & {$[.905]$} & {$[.637]$} & {$[.821]$} \\
\hline \multirow[t]{3}{*}{ Peer GPA } & .0608 & -.0412 & .0371 & -.0081 \\
\hline & (.098) & $(.029)$ & $(.024)$ & $(.019)$ \\
\hline & {$[.536]$} & {$[.157]$} & [.134] & {$[.667]$} \\
\hline Observations & 8,463 & 9,170 & 9,143 & 8,894 \\
\hline$R^{2}$ & .134 & .174 & .073 & .181 \\
\hline \multicolumn{5}{|l|}{$\begin{array}{c}p \text {-value joint significance } \\
\text { of peer personality }\end{array}$} \\
\hline $\begin{array}{l}\text { variables } \\
\text { Controlling for peer }\end{array}$ & .3407 & .0048 & .3980 & .0006 \\
\hline \multicolumn{5}{|l|}{$\begin{array}{l}\text { Controlling for peer } \\
\text { gender nationality }\end{array}$} \\
\hline $\begin{array}{l}\text { high school math } \\
\text { major and peer GPA }\end{array}$ & Yes & Yes & Yes & Yes \\
\hline \multicolumn{5}{|l|}{ Indicators for } \\
\hline scheduling conflicts & Yes & Yes & Yes & Yes \\
\hline
\end{tabular}

NotE.-The dependent variable in col. 1 is student's self-reported weekly study hours. The dependent variable in col. 2 is the instructor quality index, defined as the average of the standardized value of the four evaluation items: "Evaluate the overall functioning of your tutor in this course with a grade," "The tutor sufficiently mastered the course content," "The tutor stimulated the transfer of what I learned in this course to other contexts," and "The tutor was enthusiastic in guiding our group." The dependent variable in col. 3 is the peer interaction index, defined as the average of the standardized value of the two evaluation items "My tutorial group has functioned well" and "Working in tutorial groups with my fellow students helped me to better understand the subject matter." The dependent variable in col. 4 is based on the question "Please give an overall grade for the quality of this course." All models are estimated with ordinary least squares regressions that include measures for the respective own personality trait as well as gender, nationality (Dutch, German), third-order polynomial in GPA, course-times-year fixed effects, class size, and the number of students with nonmissing personality measures. The estimation sample of this table consists of all student-course observations with nonmissing values of the respective evaluation item(s). Table A8 shows that peer personality does not affect the survey response probability. Table A9 shows that our main results are very similar for the subsample included in this regression table. Robust standard errors clustered at the course level are in parentheses; $p$-values are reported in brackets.

need to observe instructors teaching the same courses in different years. We therefore observe teacher value added for only $64 \%$ of our estimation sample. We test whether peer personality interacts with teacher value-added measures that are based on teacher effectiveness in other 
courses.$^{23}$ If teacher and peer quality are substitutes, we would expect peer personality to be more important in classes with a low-quality teacher. When teachers are unable to explain the material, persistent peers might be able to compensate for a lack of teacher quality. If, however, teachers and peers are complements, we would expect peer personality to matter more in classes with high-quality teachers. In this case, a good teacher might be able to foster the effect that persistent peers have and, in this way, enhance student performance. Surprisingly, interaction effects between teacher and peer characteristics have not received any attention in the existing peer effects literature.

In table 8, we estimate the relationship between peer personality and grades for sections with high, medium, and low teacher quality. Column 1 in table 8 suggests that students with high-quality teachers benefit from having persistent peers, while columns 2 and 3 show that this relationship is not significant for students with lower-quality teachers. For approximately one-third of the sample, we do not have information on teacher quality. Column 4 shows that peer persistence is significantly related to grades for the part of the sample with missing information on teacher quality. Taken together, the results in table 8 provide suggestive evidence on the complementarity of teacher quality and peer persistence. The relationship between peer persistence and grades is driven by students with high-quality teachers or teachers for whom we cannot compute teacher value added. These results could suggest that high-quality teachers are more able to adjust their instruction or practices to the classroom composition and that by doing so, they bring out the best in groups with persistent students. Since we have information on teacher quality for only a subset of the students, we cannot draw firm conclusions on the extent to which the effect of persistent peers is fully or partly driven by high-quality teachers.

\section{Effects on Parallel and Subsequent Performance}

Peer personality might affect students' grades because peers affect students' human or social capital. If this is the case, peer effects may stay with the student and extend to outcomes beyond the course in which the peerto-peer interaction takes place. Having two classrooms per period and multiple periods over time allows us to analyze the effects of peer personality in one classroom on performance in parallel and subsequent classrooms.

\footnotetext{
$\approx$ For the construction of teacher value-added models, we leave out the course in which we test for personality peer effects to avoid the possibility that measures of teacher productivity pick up performance gain from peer personality.
} 
TABLE 8

Mechanisms II: Heterogeneous EfFects by Teacher Quat.tTy

\begin{tabular}{|c|c|c|c|c|}
\hline & \multicolumn{4}{|c|}{ Teacher Value-Added Subsample } \\
\hline & $\begin{array}{l}\text { High-Quality } \\
\text { Teacher } \\
\text { (1) }\end{array}$ & $\begin{array}{l}\text { Medium-Quality } \\
\text { Teacher } \\
\text { (2) }\end{array}$ & $\begin{array}{l}\text { Low-Quality } \\
\text { Teacher } \\
\text { (3) }\end{array}$ & $\begin{array}{c}\text { Missing Teacher } \\
\text { Value Added } \\
\text { (4) }\end{array}$ \\
\hline \multirow[t]{3}{*}{ Peer persistence } & .0416 & -.0175 & -.0074 & .0208 \\
\hline & $(.014)$ & $(.017)$ & $(.012)$ & (.012) \\
\hline & {$[.005]$} & {$[.297]$} & {$[.535]$} & {$[.089]$} \\
\hline \multirow[t]{3}{*}{ Peer self-confidence } & -.0104 & .0436 & .0011 & -.0032 \\
\hline & $(.012)$ & (.013) & $(.011)$ & $(.011)$ \\
\hline & {$[.386]$} & {$[.001]$} & [.921] & {$[.775]$} \\
\hline \multirow[t]{3}{*}{ Peer anxiety } & -.0062 & .0011 & .0055 & -.0017 \\
\hline & $(.012)$ & $(.011)$ & $(.011)$ & $(.009)$ \\
\hline & {$[.591]$} & {$[.925]$} & {$[.625]$} & {$[.856]$} \\
\hline \multirow[t]{3}{*}{ Peer risk attitude } & -.0148 & .0025 & -.0174 & -.0011 \\
\hline & $(.017)$ & $(.015)$ & $(.014)$ & $(.010)$ \\
\hline & [.391] & [.868] & {$[.219]$} & {$[.915]$} \\
\hline Observations & 3,583 & 3,252 & 3,556 & 5,752 \\
\hline$R^{2}$ & .643 & .654 & .620 & .666 \\
\hline \multicolumn{5}{|l|}{$\begin{array}{l}p \text {-value joint } \\
\text { significance of } \\
\text { peer personality }\end{array}$} \\
\hline variables & .0437 & .0033 & .6401 & .3243 \\
\hline \multicolumn{5}{|l|}{$\begin{array}{l}\text { Controlling for peer } \\
\text { gender nationality } \\
\text { high school math } \\
\text { major and peer }\end{array}$} \\
\hline GPA & Yes & Yes & Yes & Yes \\
\hline $\begin{array}{l}\text { Indicators for } \\
\text { scheduling } \\
\text { conflicts }\end{array}$ & Yes & Yes & Yes & Yes \\
\hline
\end{tabular}

Note. The dependent variable is the standardized course grade. Teacher quality is based on the respective tertile of teacher value added of the classroom instructor. Teacher value added is constructed with the VAM program by Stepner (2013), which follows Chetty, Friedman, and Rockoff (2014). All models are estimated with ordinary least squares regressions that include measures for the respective own personality trait as well as gender, nationality (Dutch, German), third-order polynomial in GPA, course-year fixed effects, class size, and the number of students with nonmissing personality measures. The estimation sample of cols. $1-$ 3 consists of all student-course observations with nonmissing teacher value added. The computation of teacher value added requires observing instructors teaching the same course in multiple years, which leads to missing teacher value-added measures. Robust standard errors clustered at the course level are in parentheses; $p$-values are reported in brackets.

Table 9 provides estimates how peers in a given course affect students' performance in the parallel course and subsequent courses. Column 1 shows that the effect of having persistent peers on grades in parallel courses is positive but not statistically significant. When analyzing the effect of peer persistence on grades in subsequent courses in columns 2 and 3 , we find that the point estimates are statistically significant. Column 3 shows that a 1 standard deviation increase in peer persistence raises average future grades by $1.5 \%$ of a standard deviation. The size of this 
TABLE 9

Mecinanisms III: Performance in Paralleel and Subsequent Courses

\begin{tabular}{|c|c|c|c|}
\hline & $\begin{array}{c}\text { Standardized Grade } \\
\text { Parallel Course } \\
\text { (1) }\end{array}$ & $\begin{array}{c}\text { Standardized } \\
\text { Grade Next Period } \\
(2)\end{array}$ & $\begin{array}{c}\text { Standardized Average } \\
\text { Future Grades } \\
\text { (3) }\end{array}$ \\
\hline \multirow[t]{3}{*}{ Peer persistence } & .0071 & .0117 & .0149 \\
\hline & $(.010)$ & $(.006)$ & $(.005)$ \\
\hline & {$[.467]$} & {$[.064]$} & {$[.004]$} \\
\hline \multirow[t]{3}{*}{ Peer self-confidence } & -.0036 & -.0041 & -.0017 \\
\hline & $(.010)$ & $(.008)$ & $(.007)$ \\
\hline & {$[.727]$} & {$[.620]$} & {$[.806]$} \\
\hline \multirow[t]{3}{*}{ Peer anxiety } & .0146 & .0007 & -.0064 \\
\hline & $(.011)$ & $(.007)$ & $(.007)$ \\
\hline & {$[.177]$} & {$[.921]$} & {$[.388]$} \\
\hline \multirow[t]{3}{*}{ Peer risk attitude } & .0035 & .0000 & .0053 \\
\hline & $(.010)$ & $(.007)$ & $(.007)$ \\
\hline & {$[.736]$} & [.999] & [.482] \\
\hline Observations & 7,030 & 9,422 & 9,227 \\
\hline$R^{2}$ & .567 & .559 & .572 \\
\hline \multicolumn{4}{|l|}{$p$-value joint } \\
\hline \multicolumn{4}{|l|}{$\begin{array}{l}\text { Controlling for peer } \\
\text { gender nationality }\end{array}$} \\
\hline $\begin{array}{l}\text { high school math } \\
\text { major and peer GPA }\end{array}$ & Yes & Yes & Yes \\
\hline \multicolumn{4}{|l|}{ Parallel course fixed } \\
\hline effects & Yes & Yes & Yes \\
\hline
\end{tabular}

NoTE.-The table provides an analysis of how peer personality affects performance in parallel and subsequent courses. The dependent variable in col. 1 is the standardized course grade of the parallel course taken at the same time. The dependent variable in col. 2 is the standardized average course grade obtained in the subsequent period. The dependent variable in col. 3 is the average standardized course grade obtained in all subsequent periods. All models are estimated with ordinary least squares regressions that include measures for the respective own personality trait as well as gender, nationality (Dutch, German), third-order polynomial in GPA, course-times-year fixed effects, class size, and the number of studen ts with nonmissing personality measures. The estimation sample excludes periods 1 and 2, in which peer groups in the course and parallel course are identical. Robust standard errors clustered at the course level are in parentheses; $p$-values are reported in brackets.

effect suggests a nontransient effect of peer persistence on grades. This may occur because students accumulate human or social capital by interacting with persistent peers. They may acquire more skills or build a friendship network of persistent peers from which they benefit in current and future courses. ${ }^{24}$

${ }^{24}$ Given that results in table 6 suggest that students' overall first-year performance is affected by their peers, one could be concerned that results reported in table 9 are driven by positive selection of students. However, the main conclusions remain the same when we estimate effects on subsequent performance using inverse-probability weights that account for the probability of observing an outcome. 


\section{Formation of Social Networks}

One reason that students may perform better when assigned to more persistent peers is that they interact more with them. While this may seem like a trivial point, it is not obvious that students' social interactions can be manipulated by group assignments. Carrell, Sacerdote, and West (2013) highlight the importance of endogenous friendship formation and document that the manipulation of peer-to-peer interactions can fail and backfire.

To shed light on whether students actually interact more with persistent peers when they are assigned to persistent peers, we collected information on students' first-year interactions among section peers from $2018 .^{25}$ Specifically, at the end of the first course period, we asked students the following question: "During course period 1 you were assigned to a tutorial group. Please provide up to three names (first and last name) of students from this group with whom you interact most, in order of importance. Just leave blank in case you prefer not to answer." ${ }^{26}$ This question allows us to investigate whether exposure to persistent peers is related to the persistence of students in their social network. Table 10 shows the impact of peer personality on the characteristics of the section peers that students name. Students randomly assigned to persistent section peers are more likely to report having social interaction with persistent students. Column 1 shows that a 1 standard deviation increase in the persistence of section peers increases the persistence of those students mentioned by 0.48 standard deviations. Columns 2-4 show similar effects for self-confidence, anxiety, and risk attitude.

Taken together, this evidence is consistent with the idea that building a social network that contains more persistent peers is a possible mechanism for the positive effects on contemporaneous performance. If these social networks persist and students become friends, this could also contribute to explaining the longer-run impact of peer personality on performance.

\footnotetext{
${ }^{25}$ One limitation of this analysis is that the sample for which we observe student networks does not overlap with the estimation sample we use for our main results. The evidence here should therefore be considered as suggestive.

${ }_{26}$ The survey was answered by 625 students, and $57 \%$ of the respondents provided the name of at least one student they interacted with. On the basis of the names students reported, we were unable to identify and merge seven individuals, leaving us with 354 observations. Of the students who answered this question, $79 \%$ provided the names of three students. In our analysis, we use the average personality traits of all students who can be identified. Neither peer persistence nor any other peer characteristic predicts the number of social interactions students report.
} 
TABLE 10

Mechanisms IV: Impact of Peer Personalitty on Network Formation

\begin{tabular}{|c|c|c|c|c|c|}
\hline & $\begin{array}{l}\text { Persistence of } \\
\text { the } 3 \text { Students } \\
\text { Mentioned } \\
\text { (1) }\end{array}$ & $\begin{array}{c}\text { Self- } \\
\text { Confidence } \\
\text { of the } \\
3 \text { Students } \\
\text { Mentioned } \\
\text { (2) }\end{array}$ & $\begin{array}{l}\text { Anxiety } \\
\text { of the } \\
3 \text { Students } \\
\text { Mentioned } \\
\text { (3) }\end{array}$ & $\begin{array}{l}\text { Risk Attitude } \\
\text { of the } \\
\text { 3 Students } \\
\text { Mentioned } \\
\text { (4) }\end{array}$ & $\begin{array}{l}\text { Fraction } \\
\text { of Females } \\
\text { among the } \\
3 \text { Students } \\
\text { Mentioned } \\
\text { (5) }\end{array}$ \\
\hline Peer persistence & $\begin{array}{l}.479 \\
(.058) \\
{[.000]}\end{array}$ & & & & \\
\hline $\begin{array}{l}\text { Peer } \\
\quad \text { self-confidence }\end{array}$ & & $\begin{array}{l}.456 \\
(.089) \\
{[.000]}\end{array}$ & & & \\
\hline Peer anxiety & & & $\begin{array}{l}.488 \\
(.065) \\
{[.000]}\end{array}$ & & \\
\hline Peer risk attitude & & & & $\begin{array}{l}.406 \\
(.051) \\
{[.000]}\end{array}$ & \\
\hline $\begin{array}{l}\text { Fraction of female } \\
\text { peers }\end{array}$ & & & & & $\begin{array}{l}.764 \\
(.139) \\
{[.000]}\end{array}$ \\
\hline Observations & 354 & 354 & 354 & 354 & 354 \\
\hline$R^{2}$ & .246 & .180 & .281 & .204 & .436 \\
\hline
\end{tabular}

NoTE.-All models use data on self-reported interactions collected in 2018. In an online survey at the end of the first course period, students were asked the following question: "During course period 1 you were assigned to a tutorial group. Please provide up to three names (first and last name) of students from this group with whom you interact most, in order of importance. Just leave blank in case you prefer not to answer." The dependent variables in all columns refer to the average persistence, self-confidence, anxiety, risk attitude and gender measured in week 1 of the nominated students. Peer personality is also measured in week 1 . All models are estimated with ordinary least squares regressions that include measures for the respective own personality trait measured in week 1 as well as gender, nationality (Dutch, German), study program, and the math entry test score. Robust standard errors clustered at the section level are in parentheses; $p$-values are reported in brackets.

\section{E. Heterogeneous Effects}

We investigate whether the impact of peer personality is heterogeneous, depending on the students' own levels of the respective trait. ${ }^{27}$ On the basis of the students' own trait measures, we categorize students as having low $\left(P_{i}^{\mathrm{l}}\right)$, medium $\left(P_{i}^{\mathrm{m}}\right)$, or high $\left(P_{i}^{\mathrm{h}}\right)$ levels of a particular trait, depending

${ }^{27}$ We also tested whether the impact of peer personality differs by course content. Table A11 provides suggestive evidence that peer persistence is more important in less mathematical courses than in more mathematical courses. This result could provide an explanation for the peer effects in course choices reported in table A7. The positive impact of persistent peers in less mathematical courses may incline students to believe that they are relatively better prepared for less mathematical courses. 
on the tertile to which they belong. ${ }^{28}$ We then interact students' own trait type with the peer personality measure, and estimate

$$
\begin{aligned}
A_{i g g}= & \overline{\mathrm{PP}}_{\mathrm{g}-i} \times\left(P_{i}^{\mathrm{l}} \alpha_{1}^{\prime}+P_{i}^{\mathrm{m}} \alpha_{2}^{\prime}+P_{i}^{\mathrm{h}} \alpha_{s}^{\prime}\right) \\
& +P_{i}^{\mathrm{l}} \beta_{4}^{\prime}+P_{i}^{\mathrm{m}} \beta_{5}^{\prime}+P_{i}^{\mathrm{h}} \beta_{6}^{\prime}+X_{i} \gamma^{\prime}+\rho_{i c}+u_{i g g} .
\end{aligned}
$$

Table 11 reports the estimates of this model, which allows for heterogeneous effects. Column 1 shows that students in the bottom and top tertiles of the persistence distribution particularly benefit from a group of peers with high persistence. Students with medium persistence are not significantly affected when they are exposed to more persistent peers. Column 2 shows that the results are again robust to the inclusion of other peer characteristics. ${ }^{29}$ Columns 3 and 4 reveal that the effects that persist into future courses are driven by the same subgroup of students that cause the contemporaneous effects.

We next turn to the question of whether peers who score very high or very low on specific personality measures influence performance in the same way as the average peer personality in the group. For instance, having very persistent peers (shining lights) may be particularly beneficial for performance. Or peers who have very limited persistence (bad apples) may be particularly detrimental for performance. We test for such nonlinearities by running regressions replacing the linear-in-means specification by the proportion of peers that belong to the top and bottom $10 \%$ of the overall distribution. Column 1 in table 12 suggests that students significantly benefit from students in the top $10 \%$ of the persistence distribution, while they do not suffer from peers at the bottom $10 \%$ of the persistence distribution. We find also that students benefit from exposure to peers who are very unwilling to take risks.

\section{Conclusion}

Previous literature on peer effects has studied the extent to which student performance depends on fellow students' achievement, gender, and race. This paper focuses on a different aspect of student interaction and shows that peer personality affects student achievement in university. To identify the causal impact of peers, we exploit the random assignment of students to university teaching sections.

Our results show that students who are exposed to more persistent peers achieve higher grades. Peers' risk tolerance, self-confidence, and

\footnotetext{
${ }_{28}$ Tertiles are based on the global distribution and thus not defined at the section level.

${ }^{29}$ We also tested whether peer effects are heterogeneous by GPA of the student. Results are reported in table A12. Students with a high GPA and those with a low GPA benefit most from persistent peers. Having risk-tolerant peers has the largest negative effect on performance among students from the bottom GPA tertile.
} 
TABLE 11

Effect of Peer Personality on Student Performance: Heterogeneous Effects

\begin{tabular}{|c|c|c|c|c|}
\hline & \multicolumn{2}{|c|}{$\begin{array}{c}\text { STANDARDIZED } \\
\text { GRADE }\end{array}$} & \multicolumn{2}{|c|}{$\begin{array}{c}\text { AvERAGE FUTURE } \\
\text { GRADES }\end{array}$} \\
\hline & (1) & (2) & (3) & (4) \\
\hline \multirow[t]{3}{*}{ Low persistence $\times$ peer persistence } & .0269 & .0265 & .0185 & .0188 \\
\hline & $(.009)$ & $(.009)$ & $(.008)$ & $(.009)$ \\
\hline & {$[.005]$} & {$[.006]$} & {$[.028]$} & {$[.031]$} \\
\hline \multirow[t]{3}{*}{ Medium persistence $\times$ peer persistence } & .0098 & .0093 & -.0004 & .0003 \\
\hline & $(.008)$ & $(.008)$ & $(.009)$ & $(.009)$ \\
\hline & {$[.215]$} & [.239] & {$[.961]$} & {$[.972]$} \\
\hline \multirow{3}{*}{ High persistence $\times$ peer persistence } & .0159 & .0153 & .0253 & .0258 \\
\hline & $(.009)$ & $(.009)$ & $(.011)$ & $(.011)$ \\
\hline & {$[.077]$} & {$[.091]$} & {$[.021]$} & {$[.025]$} \\
\hline \multirow{3}{*}{ Low self-confidence $\times$ peer self-confidence } & .0024 & .0026 & .0009 & .0018 \\
\hline & $(.009)$ & $(.009)$ & $(.009)$ & $(.010)$ \\
\hline & {$[.784]$} & {$[.766]$} & [.922] & {$[.855]$} \\
\hline \multicolumn{5}{|l|}{ Medium self-confidence $\times$ peer } \\
\hline \multirow[t]{3}{*}{ self-confidence } & .0074 & .0078 & .0026 & .0026 \\
\hline & $(.012)$ & $(.012)$ & $(.010)$ & $(.010)$ \\
\hline & {$[.526]$} & {$[.501]$} & [.795] & {$[.789]$} \\
\hline \multicolumn{5}{|l|}{ High self-confidence $\times$ peer } \\
\hline \multirow[t]{3}{*}{ self-confidence } & -.0055 & -.0051 & -.0067 & -.0061 \\
\hline & $(.010)$ & $(.009)$ & $(.012)$ & $(.011)$ \\
\hline & {$[.571]$} & {$[.590]$} & {$[.591]$} & {$[.587]$} \\
\hline \multirow{3}{*}{ Low anxiety $\times$ peer anxiety } & -.0105 & -.0117 & -.0148 & -.0139 \\
\hline & $(.008)$ & $(.008)$ & $(.012)$ & $(.012)$ \\
\hline & {$[.207]$} & {$[.161]$} & {$[.214]$} & {$[.245]$} \\
\hline \multirow[t]{3}{*}{ Medium anxiety $\times$ peer anxiety } & .0015 & .0003 & -.0251 & -.0248 \\
\hline & $(.010)$ & $(.011)$ & $(.009)$ & $(.009)$ \\
\hline & {$[.885]$} & {$[.976]$} & {$[.009]$} & {$[.009]$} \\
\hline \multirow[t]{3}{*}{ High anxiety $\times$ peer anxiety } & .0080 & .0068 & .0214 & .0221 \\
\hline & $(.008)$ & $(.008)$ & $(.009)$ & $(.009)$ \\
\hline & {$[.331]$} & {$[.414]$} & {$[.018]$} & {$[.018]$} \\
\hline \multirow[t]{3}{*}{ Low risk $\times$ peer risk attitude } & .0031 & .0034 & .0112 & .0100 \\
\hline & $(.009)$ & $(.009)$ & $(.012)$ & $(.012)$ \\
\hline & {$[.726]$} & {$[.715]$} & {$[.351]$} & {$[.407]$} \\
\hline \multirow[t]{3}{*}{ Medium risk $\times$ peer risk attitude } & -.0111 & -.0108 & .0083 & .0073 \\
\hline & $(.008)$ & $(.008)$ & $(.008)$ & $(.008)$ \\
\hline & {$[.181]$} & {$[.180]$} & {$[.310]$} & {$[.379]$} \\
\hline \multirow[t]{3}{*}{ High risk $\times$ peer risk attitude } & -.0260 & -.0258 & .0009 & .0009 \\
\hline & $(.011)$ & $(.011)$ & $(.011)$ & $(.011)$ \\
\hline & {$[.020]$} & {$[.022]$} & {$[.935]$} & {$[.936]$} \\
\hline Observations & 16,155 & 16,155 & 9,227 & 9,227 \\
\hline$R^{2}$ & .644 & .644 & .573 & .574 \\
\hline$p$-value joint significance of peer variables & .0014 & .0050 & $<.0001$ & $<.0001$ \\
\hline \multicolumn{5}{|l|}{ Controlling for peer gender, nationality, } \\
\hline GPA, and high school math major & No & Yes & No & Yes \\
\hline Indicators for scheduling conflicts & Yes & Yes & Yes & Yes \\
\hline
\end{tabular}

NoтE.-The dependent variable in cols. 1 and 2 is the standardized course grade. The dependent variable in cols. 3 and 4 is the standardized average future course grades. All models are estimated with ordinary least squares regressions that include dummies for the respective own personality trait tertile, gender, nationality (Dutch, German), third-order polynomial in GPA, course-year fixed effects, class size, and the number of students with nonmissing personality measures. Robust standard errors clustered at the course level are in parentheses; $p$-values are reported in brackets. 
TABLE 12

Peer Personality: Bad Apples nNd Simning Lights

\begin{tabular}{|c|c|c|c|c|c|c|c|}
\hline & \multicolumn{6}{|c|}{ Standardized Grade } & \multirow{2}{*}{$\begin{array}{c}\text { Average } \\
\text { Future } \\
\text { Grades } \\
\text { (7) }\end{array}$} \\
\hline & (1) & (2) & (3) & (4) & (5) & (6) & \\
\hline \multicolumn{8}{|l|}{ Proportion of top } \\
\hline \multirow[t]{3}{*}{$10 \%$ persistence peers } & .1047 & & & & .0908 & .0852 & .0401 \\
\hline & $(.049)$ & & & & $(.057)$ & $(.053)$ & $(.065)$ \\
\hline & {$[.035]$} & & & & {$[.112]$} & {$[.108]$} & {$[.535]$} \\
\hline \multicolumn{8}{|l|}{ Proportion of bottom } \\
\hline \multirow[t]{3}{*}{$10 \%$ persistence peers } & -.0431 & & & & -.0452 & -.0426 & -.0458 \\
\hline & $(.059)$ & & & & $(.058)$ & $(.058)$ & $(.064)$ \\
\hline & {$[.466]$} & & & & {$[.435]$} & {$[.459]$} & {$[.476]$} \\
\hline \multicolumn{8}{|l|}{ Proportion of top } \\
\hline \multirow{3}{*}{$10 \%$ self-confidence peers } & & .0445 & & & -.0043 & -.0029 & -.0428 \\
\hline & & $(.051)$ & & & $(.056)$ & $(.057)$ & $(.073)$ \\
\hline & & {$[.384]$} & & & {$[.938]$} & {$[.960]$} & {$[.559]$} \\
\hline \multicolumn{8}{|l|}{ Proportion of bottom } \\
\hline \multirow[t]{3}{*}{$10 \%$ self-confidence peers } & & -.0228 & & & .0099 & .0091 & -.0417 \\
\hline & & $(.059)$ & & & $(.060)$ & $(.052)$ & $(.060)$ \\
\hline & & {$[.699]$} & & & {$[.869]$} & {$[.861]$} & {$[.489]$} \\
\hline \multirow{4}{*}{$\begin{array}{l}\text { Proportion of top } 10 \% \text { anxiety } \\
\text { peers }\end{array}$} & & & & & & & \\
\hline & & & .0058 & & .0060 & -.0032 & -.0839 \\
\hline & & & $(.056)$ & & $(.054)$ & $(.054)$ & $(.064)$ \\
\hline & & & {$[.917]$} & & {$[.911]$} & {$[.952]$} & {$[.188]$} \\
\hline \multicolumn{8}{|l|}{ Proportion of bottom } \\
\hline \multirow[t]{3}{*}{$10 \%$ anxiety peers } & & & .0724 & & .0710 & .0759 & .0190 \\
\hline & & & $(.050)$ & & $(.047)$ & $(.056)$ & $(.068)$ \\
\hline & & & [.153] & & {$[.134]$} & {$[.176]$} & {$[.780]$} \\
\hline \multirow{4}{*}{$\begin{array}{l}\text { Proportion of top } 10 \% \text { risk } \\
\text { attitude peers }\end{array}$} & & & & & & & \\
\hline & & & & .0232 & .0093 & .0141 & .0618 \\
\hline & & & & $(.042)$ & $(.041)$ & $(.041)$ & $(.047)$ \\
\hline & & & & {$[.581]$} & {$[.822]$} & [.732] & {$[.187]$} \\
\hline \multicolumn{8}{|l|}{ Proportion of bottom } \\
\hline \multirow[t]{3}{*}{$10 \%$ risk attitude peers } & & & & .1428 & .1324 & .1305 & .0405 \\
\hline & & & & $(.054)$ & $(.054)$ & $(.051)$ & $(.056)$ \\
\hline & & & & {$[.010]$} & {$[.017]$} & {$[.011]$} & {$[.474]$} \\
\hline Observations & 16,155 & 16,155 & 16,155 & 16,155 & 16,155 & 16,155 & 9,227 \\
\hline$R^{2}$ & .644 & .644 & .644 & .644 & .644 & .644 & .572 \\
\hline \multicolumn{8}{|l|}{$p$-value joint significance } \\
\hline \multirow{2}{*}{\multicolumn{8}{|c|}{$\begin{array}{l}\text { Controlling for peer gender, } \\
\text { nationality, GPA, and high }\end{array}$}} \\
\hline & & & & & & & \\
\hline \multicolumn{8}{|l|}{ Indicators for scheduling } \\
\hline $\begin{array}{l}\text { Indicators for scheduling } \\
\text { conflicts }\end{array}$ & Yes & Yes & Yes & Yes & Yes & Yes & Yes \\
\hline
\end{tabular}

Note. - The dependent variable in cols. 1-6 is the standardized course grade. The dependent variable in col. 7 is the standardized average future course grade. All models are estimated with ordinary least squares regressions that include measures for the respective own personality trait as well as gender, nationality (Dutch and German), third-order polynomial in GPA, course-times-year fixed effects, class size, and the number of students with nonmissing personality measures. Additional controls include indicators for own top and bottom $10 \%$ status for each of the four traits. Robust standard errors clustered at the course level are in parentheses; $p$-values are reported in brackets. 
anxiety do not significantly affect performance. We provide evidence that these personality peer effects are distinct from achievement peer effects. We also study the heterogeneity of personality peer effects and find that both students with high persistence and those with low persistence benefit most from having highly persistent peers. Moreover, we investigate possible underlying mechanisms and find no evidence that students change their self-reported study hours when exposed to persistent peers. Students' evaluations of teachers also do not appear to be affected by persistent peers. We do, however, find suggestive evidence for complementarity between teacher quality and peer persistence. Importantly, we also find that the effect of persistent peers is nontransient: exposure to persistent peers also increases grades in future periods. This suggests a human or social capital effect: students who meet persistent peers at the beginning of their studies may develop better learning habits and a different social network that yields academic returns.

An inherent concern in the literature on personality traits is that other correlated factors may drive observed relationships. We believe that even if there are unobserved variables correlated with personality, it is still important to know that measures of peer personality are picking up a trait that creates spillovers. From a policy perspective, it is important to know that exposure to persistent peers creates learning spillovers. It is not necessarily important to know which traits correlated with persistence drive the result. As long as peer personality has predictive power for social spillovers, policies can be based on it.

The results documented in this paper also have three important implications for the design of interventions and education policies that aim to improve socioemotional skills. First, in settings in which treated and nontreated students interact, changes in peer personality may positively affect the educational attainment of nontreated students, which will make it more difficult to detect an intervention impact. Second, and more generally, the social returns of any intervention that enhances socioemotional skills will be underestimated if positive spillovers of personality on other individuals outside the studied environment are neglected. Finally, if peers with a certain personality affect performance through particular behavior, then policy could also be targeted at stimulating that behavior directly. Future research could collect detailed behavioral measures to shed light on the mechanisms of personality peer effects. 


\section{Appendix A}

\section{Additional Results}
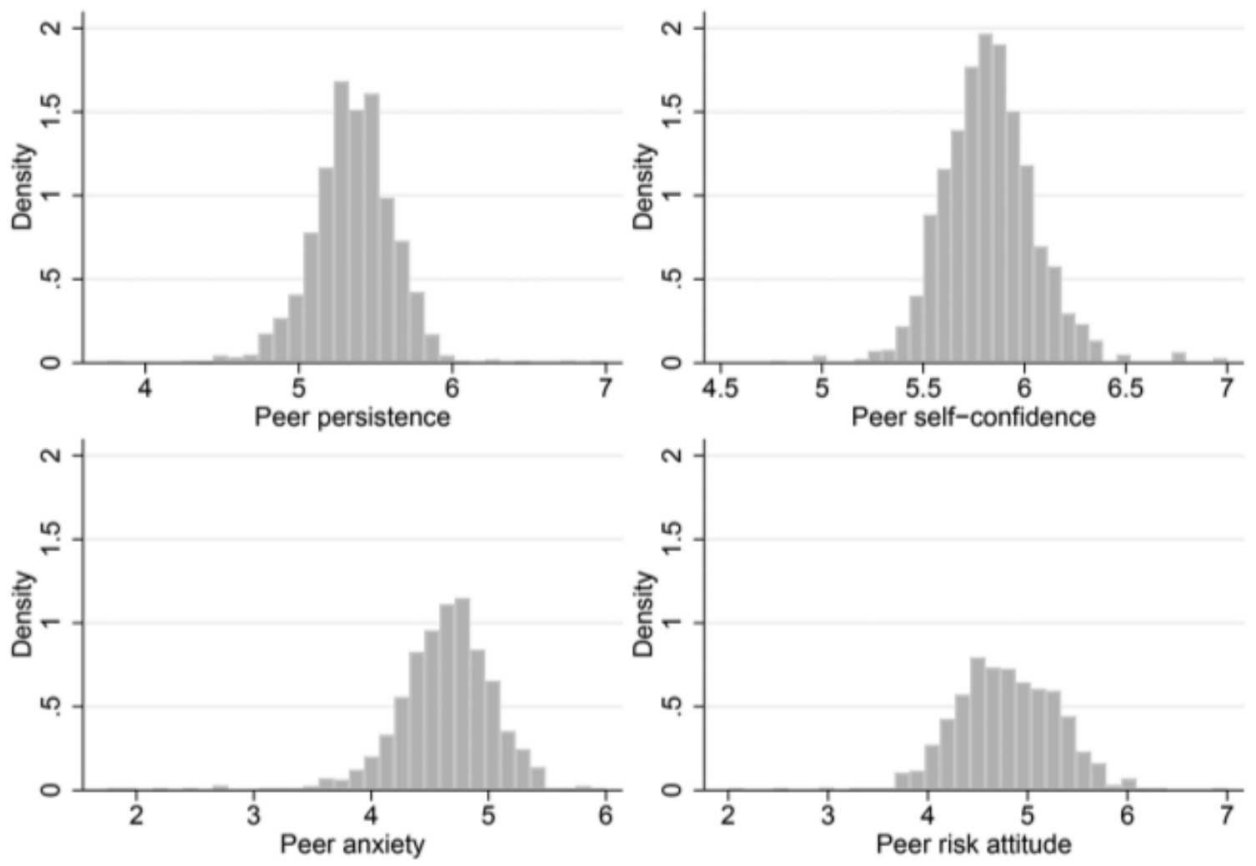

FIG. A1.-Variation in peer personality. A color version of this figure is available online. 

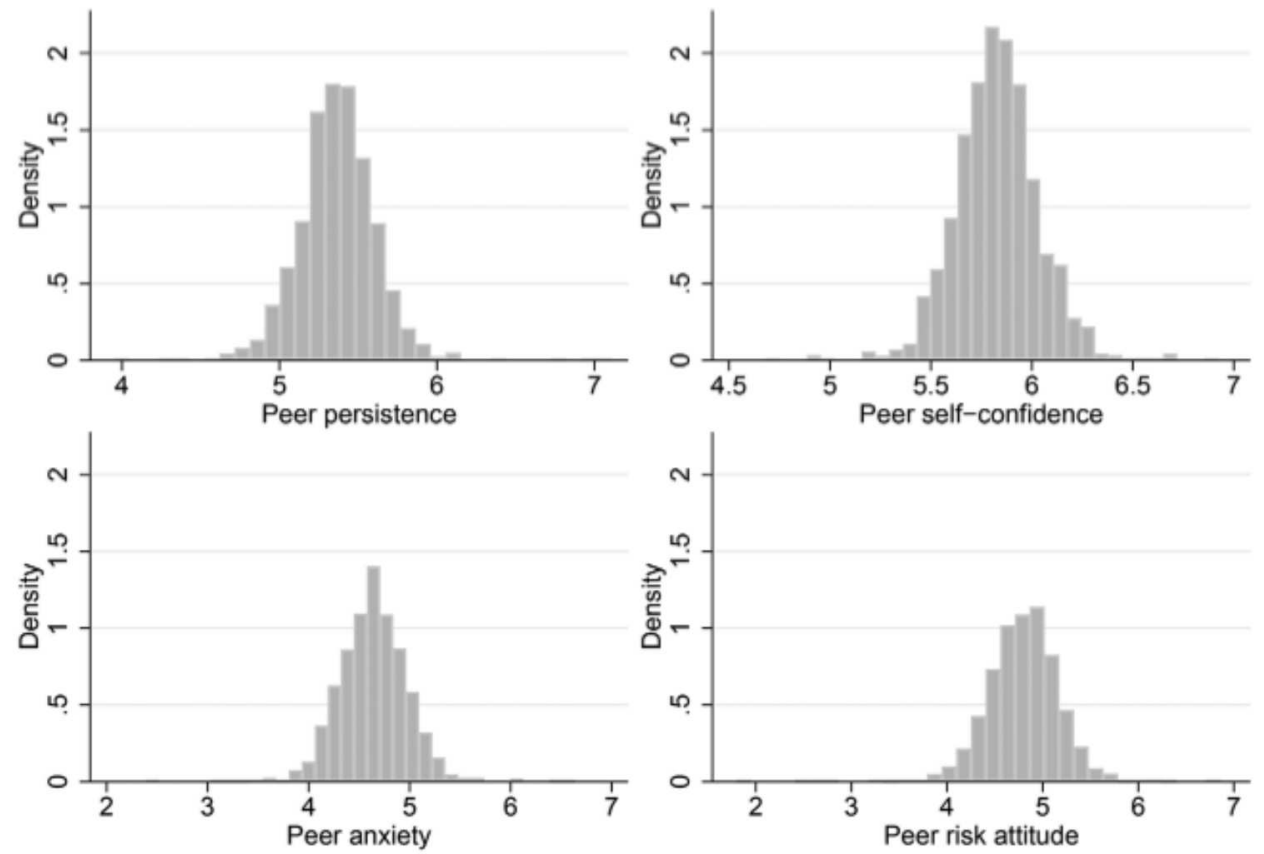

FIG. A2. Variation in peer personality after course-times-year fixed effects are taken out A color version of this figure is available online.

TABLE A1

Pairwise Correlations between Measures of Student Personality

\begin{tabular}{lcccc}
\hline \hline & $\begin{array}{c}\text { Persistence } \\
(1)\end{array}$ & $\begin{array}{c}\text { Self-Confidence } \\
(2)\end{array}$ & $\begin{array}{c}\text { Anxiety } \\
(3)\end{array}$ & $\begin{array}{c}\text { Risk Attitude } \\
(4)\end{array}$ \\
\hline Persistence & 1 & & & \\
Self-confidence & .4579 & 1 & & \\
& {$[.000]$} & -.1842 & 1 & \\
Anxiety & -.0268 & {$[.000]$} & & \\
& {$[.085]$} & .1068 & -.1299 & 1 \\
Risk attitude & .0202 & {$[.000]$} & {$[.000]$} & \\
& {$[.200]$} & & & \\
& & & & \\
\end{tabular}

NotE. - The table shows student-level pairwise correlations between the measures of student personality we use throughout the paper. $N=4,383$; $p$-values are reported in brackets. 
TABLE A2

RANDOMization Check for the SAmple with Nonmissing Grades

\begin{tabular}{|c|c|c|c|c|c|}
\hline & $\begin{array}{c}\text { Peer } \\
\text { Persistence } \\
\text { (1) }\end{array}$ & $\begin{array}{l}\text { Peer Self-Con- } \\
\text { fidence } \\
(2)\end{array}$ & $\begin{array}{c}\text { Peer } \\
\text { Anxiety } \\
(3)\end{array}$ & $\begin{array}{l}\text { Peer Risk } \\
\text { Attitude } \\
\quad(4)\end{array}$ & $\begin{array}{c}\text { Proportion of Peers } \\
\text { with High School } \\
\text { Math Major } \\
\text { (5) }\end{array}$ \\
\hline Persistence & $\begin{array}{l}.0055 \\
(.016) \\
{[.737]}\end{array}$ & & & & \\
\hline Self-confidence & & $\begin{array}{r}-.0018 \\
(.012) \\
{[.879]}\end{array}$ & & & \\
\hline Anxiety & & & $\begin{array}{c}-.0133 \\
(.012) \\
{[.291]}\end{array}$ & & \\
\hline Risk attitude & & & & $\begin{array}{c}-.0019 \\
(.013) \\
{[.884]}\end{array}$ & \\
\hline $\begin{array}{l}\text { High school } \\
\text { math major }\end{array}$ & & & & & $\begin{array}{l}.0031 \\
(.003) \\
{[.335]}\end{array}$ \\
\hline Observations & 16,155 & 16,155 & 16,155 & 16,155 & 16,155 \\
\hline$R^{2}$ & .167 & .131 & .242 & .447 & .166 \\
\hline
\end{tabular}

NoTE. - The dependent variable in all columns is the standardized section-level leaveout mean of the respective personality characteristic, i.e., the average peer persistence in a section, excluding the student's own personality. All models are estimated with ordinary least squares regressions that include course-times-year fixed effects and controls for gender and nationality (Dutch, German). Following the Guryan, Kroft, and Notowidigdo (2009) correction method, we control for the course-level leave-out mean in all estimations. Robust standard errors clustered at the course level are in parentheses; $p$-values are reported in brackets.

TABLE A3

Peer Personal.tTy and Course Dropout

\begin{tabular}{|c|c|c|c|c|c|c|c|}
\hline & (1) & (2) & (3) & (4) & (5) & (6) & (7) \\
\hline Peer persistence & $\begin{array}{r}.0017 \\
(.002) \\
{[.475]}\end{array}$ & & & & $\begin{array}{l}.0015 \\
(.003) \\
{[.558]}\end{array}$ & $\begin{array}{l}.0015 \\
(.003) \\
{[.559]}\end{array}$ & $\begin{array}{c}.0006 \\
(.003) \\
{[.813]}\end{array}$ \\
\hline Peer self-confidence & & $\begin{array}{c}.0005 \\
(.002) \\
{[.819]}\end{array}$ & & & $\begin{array}{c}-.0005 \\
(.002) \\
{[.852]}\end{array}$ & $\begin{array}{c}.0001 \\
(.002) \\
{[.963]}\end{array}$ & $\begin{array}{c}.0004 \\
(.002) \\
{[.866]}\end{array}$ \\
\hline Peer anxiety & & & $\begin{array}{c}-.0007 \\
(.002) \\
{[.746]}\end{array}$ & & $\begin{array}{r}-.0001 \\
(.002) \\
{[.957]}\end{array}$ & $\begin{array}{c}.0001 \\
(.002) \\
{[.958]}\end{array}$ & $\begin{array}{r}-.0007 \\
(.002) \\
{[.780]}\end{array}$ \\
\hline Peer risk attitude & & & & $\begin{array}{r}-.0042 \\
(.002) \\
{[.086]}\end{array}$ & $\begin{array}{c}-.0035 \\
(.003) \\
{[.181]}\end{array}$ & $\begin{array}{c}-.0037 \\
(.003) \\
{[.158]}\end{array}$ & $\begin{array}{r}-.0033 \\
(.003) \\
{[.205]}\end{array}$ \\
\hline $\begin{array}{l}\text { Observations } \\
R^{2}\end{array}$ & $\begin{array}{c}17,512 \\
.176\end{array}$ & $\begin{array}{c}17,512 \\
.176\end{array}$ & $\begin{array}{c}17,512 \\
.175\end{array}$ & $\begin{array}{c}17,512 \\
.175\end{array}$ & $\begin{array}{c}17,512 \\
.177\end{array}$ & $\begin{array}{c}17,512 \\
.179\end{array}$ & $\begin{array}{c}17,512 \\
.179\end{array}$ \\
\hline
\end{tabular}


TABLE A3 (Continued)

\begin{tabular}{llllllll}
\hline \hline & $(1)$ & $(2)$ & $(3)$ & $(4)$ & $(5)$ & $(6)$ & $(7)$ \\
$\begin{array}{l}\text { Controlling for peer } \\
\text { gender, nationality, } \\
\text { high school math } \\
\text { major and peer } \\
\text { GPA }\end{array}$ \\
$\begin{array}{l}\text { Indicators for sched- } \\
\text { uling conflicts }\end{array}$
\end{tabular}

TABLE A4

Robustness to Including Additional. Measures of Cognitive Abil.ity

\begin{tabular}{|c|c|c|c|c|c|c|}
\hline & (1) & (2) & (3) & (4) & (5) & (6) \\
\hline \multirow[t]{3}{*}{ Peer persistence } & .0179 & .0175 & .0175 & .0174 & .0172 & .0171 \\
\hline & $(.006)$ & $(.006)$ & $(.006)$ & $(.006)$ & $(.006)$ & $(.006)$ \\
\hline & {$[.005]$} & {$[.007]$} & {$[.007]$} & {$[.008]$} & {$[.009]$} & {$[.009]$} \\
\hline \multirow[t]{3}{*}{ Peer self-confidence } & .0010 & .0012 & .0011 & -.0002 & .0017 & .0010 \\
\hline & $(.007)$ & $(.006)$ & $(.006)$ & $(.006)$ & (.006) & $(.006)$ \\
\hline & {$[.885]$} & {$[.855]$} & {$[.864]$} & {$[.971]$} & {$[.792]$} & {$[.870]$} \\
\hline \multirow[t]{3}{*}{ Peer anxiety } & -.0010 & -.0017 & -.0023 & -.0020 & -.0028 & -.0020 \\
\hline & $(.005)$ & $(.005)$ & $(.005)$ & $(.005)$ & $(.005)$ & $(.005)$ \\
\hline & {$[.838]$} & [.742] & {$[.650]$} & {$[.706]$} & {$[.597]$} & {$[.708]$} \\
\hline \multirow[t]{3}{*}{ Peer risk attitude } & -.0114 & -.0110 & -.0109 & -.0103 & -.0099 & -.0100 \\
\hline & $(.005)$ & $(.005)$ & $(.006)$ & $(.006)$ & $(.006)$ & $(.006)$ \\
\hline & {$[.041]$} & {$[.046]$} & {$[.054]$} & {$[.068]$} & {$[.078]$} & {$[.074]$} \\
\hline Observations & 16,155 & 16,155 & 16,155 & 16,032 & 16,039 & 15,982 \\
\hline$R^{2}$ & .644 & .644 & .644 & .644 & .645 & .645 \\
\hline Indicators for scheduling conflicts & Yes & Yes & Yes & Yes & Yes & Yes \\
\hline $\begin{array}{l}\text { Controlling for peer gender } \\
\text { and nationality }\end{array}$ & No & Yes & Yes & Yes & Yes & Yes \\
\hline $\begin{array}{l}\text { Controlling for peer high school } \\
\text { math major and GPA }\end{array}$ & No & No & Yes & Yes & Yes & Yes \\
\hline $\begin{array}{l}\text { Controlling for peer math entry } \\
\text { test score }\end{array}$ & No & No & No & Yes & No & Yes \\
\hline $\begin{array}{l}\text { Controlling for peer statistics entry } \\
\text { test score }\end{array}$ & No & No & No & No & Yes & Yes \\
\hline
\end{tabular}

NoTE.- The dependent variable in all columns is the standardized course grade. All models are estimated with ordinary least squares regressions that include measures for the respective own personality trait as well as gender, nationality (Dutch and German), course-times-year fixed effects, class size, and the number of students with nonmissing personality measures. In cols. 2-6, we include third-order polynomial in GPA and a dummy indicating whether the student was a math major. The estimation sample of this table consists of all student-course observations with nonmissing grades. The number of observations is lower in cols. 4-6 due to missing values of math and statistics test scores. Robust standard errors clustered at the course level are in parentheses; p-values are reported in brackets. 


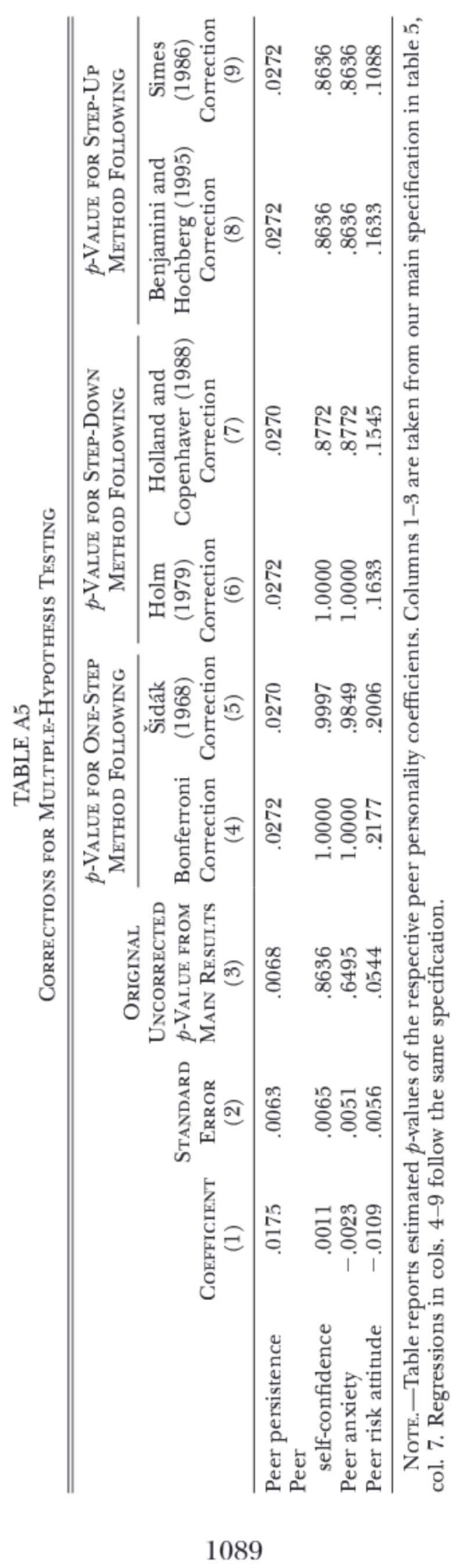


TABLE A6

Main Results with Standard Errors Clustered at tie Section Levei.

\begin{tabular}{|c|c|c|c|c|c|c|c|}
\hline & (1) & (2) & (3) & (4) & (5) & (6) & (7) \\
\hline \multirow[t]{3}{*}{ Peer persistence } & .0193 & & & & .0186 & .0180 & .0175 \\
\hline & $(.005)$ & & & & (.006) & $(.006)$ & $(.006)$ \\
\hline & {$[.000]$} & & & & {$[.001]$} & {$[.003]$} & {$[.003]$} \\
\hline \multirow[t]{3}{*}{ Peer self-confidence } & & .0085 & & & .0008 & .0010 & .0011 \\
\hline & & $(.005)$ & & & $(.006)$ & $(.006)$ & $(.006)$ \\
\hline & & {$[.090]$} & & & {$[.885]$} & {$[.846]$} & {$[.846]$} \\
\hline \multirow[t]{3}{*}{ Peer anxiety } & & & -.0015 & & -.0011 & -.0012 & -.0023 \\
\hline & & & $(.005)$ & & $(.005)$ & $(.005)$ & $(.006)$ \\
\hline & & & [.772] & & {$[.842]$} & {$[.679]$} & {$[.679]$} \\
\hline \multirow[t]{3}{*}{ Peer risk attitude } & & & & -.0111 & -.0114 & -.0116 & -.0109 \\
\hline & & & & $(.006)$ & $(.006)$ & $(.006)$ & $(.006)$ \\
\hline & & & & {$[.073]$} & {$[.075]$} & {$[.089]$} & {$[.089]$} \\
\hline Observations & 16,155 & 16,155 & 16,155 & 16,155 & 16,155 & 16,155 & 16,155 \\
\hline \multirow{2}{*}{\multicolumn{8}{|c|}{$\begin{array}{l}\text { Controlling for peer GPA, } \\
\text { gender, nationality, and }\end{array}$}} \\
\hline & & & & & & & \\
\hline high school math major & No & No & No & No & No & No & Yes \\
\hline \multirow{2}{*}{$\begin{array}{l}\text { Indicators for scheduling } \\
\text { conflicts }\end{array}$} & & & & & & & \\
\hline & No & No & No & No & No & Yes & Yes \\
\hline
\end{tabular}

NotE. The dependent variable in all columns is the standardized course grade. All models are estimated with ordinary least squares regressions that include measures for the respective own personality trait as well gender, nationality (Dutch and German), third-order polynomial in GPA, course-times-year fixed effects, class size, and the number of students with nonmissing personality measures. Robust standard errors clustered at the section level are in parentheses; $p$-values are reported in brackets.

TABLE A7

Choice of Harder or Easier Classes as Elective Courses

\begin{tabular}{lccc}
\hline \hline & $\begin{array}{c}\text { Choosing Any } \\
\text { Mathematical Elective } \\
(1)\end{array}$ & $\begin{array}{c}\text { Difficulty of Elective } \\
\text { Courses } \\
(2)\end{array}$ & $\begin{array}{c}\text { Peer Persistence } \\
\text { in Elective Courses } \\
(3)\end{array}$ \\
\hline Peer persistence & -.0103 & -.0025 & -.0026 \\
& $(.005)$ & $(.003)$ & $(.004)$ \\
Peer self-confidence & {$[.062]$} & {$[.338]$} & {$[.473]$} \\
& -.0022 & -.0002 & -.0005 \\
Peer anxiety & $(.009)$ & $(.002)$ & $(.004)$ \\
& {$[.816]$} & {$[.916]$} & {$[.901]$} \\
Peer risk attitude & .0143 & -.0099 & -.0015 \\
& $(.009)$ & $(.004)$ & $(.003)$ \\
Observations & {$[.140]$} & {$[.014]$} & {$[.627]$} \\
$R^{2}$ & -.0114 & -.0050 & -.0023 \\
& $(.007)$ & $(.004)$ & $(.004)$ \\
& {$[.104]$} & {$[.174]$} & {$[.594]$} \\
& 3,906 & 3,906 & 2,471 \\
& .195 & .565 & .368
\end{tabular}


TABLE A7 (Continued)

\begin{tabular}{|c|c|c|c|}
\hline & $\begin{array}{l}\text { Choosing Any } \\
\text { Mathematical Elective } \\
\text { (1) }\end{array}$ & $\begin{array}{l}\text { Difficulty of Elective } \\
\text { Courses } \\
(2)\end{array}$ & $\begin{array}{c}\text { Peer Persistence } \\
\text { in Elective Courses } \\
\text { (3) }\end{array}$ \\
\hline $\begin{array}{l}\text { Controlling for peer } \\
\text { gender nationality } \\
\text { and high school } \\
\text { math major }\end{array}$ & Yes & Yes & Yes \\
\hline $\begin{array}{l}\text { Parallel course fixed } \\
\text { effects }\end{array}$ & Yes & Yes & Yes \\
\hline
\end{tabular}

Note. The dependent variable in col. 1 is an indicator for students choosing at least one mathematical elective in the second or third year. The dependent variable in col. 2 is average GPA of peers across all second- and third-year elective courses. All regressions include measures for the respective own personality trait as well as course-times-year fixed effects, gender, and nationality (Dutch, German), third-order polynomial in GPA, class size, as well as the number of students with nonmissing personality measures. The estimation sample of this table consists of all student-course observations with nonmissing course choices. Robust standard errors clustered at the course level are in parentheses; $p$-values are reported in brackets.

TABLE A8

Peer Personality and Course Evaluation Survey Response

\begin{tabular}{lc}
\hline \hline & Course Evaluation Response \\
& $(1)$ \\
\hline Peer persistence & -.0049 \\
& $(.005)$ \\
Peer self-confidence & {$[.299]$} \\
& .0018 \\
Peer anxiety & $(.005)$ \\
& {$[.746]$} \\
Peer risk attitude & .0062 \\
& $(.005)$ \\
& {$[.258]$} \\
Observations & -.0049 \\
$R^{2}$ & $(.006)$ \\
Mean dependent variable & {$[.385]$} \\
$p$-value joint significance & 17,512 \\
of peer variables & .173 \\
& .4943 \\
\hline
\end{tabular}

NoTE.-The dependent variable is an indicator for students' participation in the course evaluations. The response rate is $49 \%$. The model is estimated with ordinary least squares regressions that include measures for the respective own personality trait as well gender, nationality (Dutch and German), third-order polynomial in GPA, course-timesyear fixed effects, class size, and the number of students with nonmissing personality measures. Robust standard errors clustered at the course level are in parentheses; $p$-values are reported in brackets. 
TABLE A9

Main Results for Students Who Participated in Student Course Evaluations

\begin{tabular}{|c|c|c|c|c|c|c|c|}
\hline & (1) & (2) & (3) & (4) & (5) & (6) & (7) \\
\hline \multirow[t]{3}{*}{ Peer persistence } & .0191 & & & & .0195 & .0187 & .0186 \\
\hline & $(.007)$ & & & & $(.008)$ & $(.008)$ & $(.008)$ \\
\hline & {$[.008]$} & & & & {$[.017]$} & {$[.023]$} & [.032] \\
\hline \multirow[t]{3}{*}{ Peer self-confidence } & & .0063 & & & -.0021 & -.0008 & -.0005 \\
\hline & & $(.008)$ & & & $(.010)$ & $(.010)$ & $(.010)$ \\
\hline & & {$[.463]$} & & & {$[.836]$} & {$[.935]$} & {$[.957]$} \\
\hline \multirow[t]{3}{*}{ Peer anxiety } & & & -.0011 & & .0007 & .0007 & .0011 \\
\hline & & & $(.008)$ & & $(.007)$ & $(.007)$ & $(.007)$ \\
\hline & & & {$[.882]$} & & [.925] & {$[.928]$} & {$[.880]$} \\
\hline \multirow[t]{3}{*}{ Peer risk attitude } & & & & -.0101 & -.0088 & -.0087 & -.0081 \\
\hline & & & & $(.007)$ & $(.007)$ & $(.007)$ & $(.008)$ \\
\hline & & & & {$[.142]$} & {$[.220]$} & {$[.234]$} & [.295] \\
\hline Observations & 8,463 & 8,463 & 8,463 & 8,463 & 8,463 & 8,463 & 8,463 \\
\hline$R^{2}$ & .652 & .651 & .652 & .651 & .652 & .655 & .656 \\
\hline \multicolumn{8}{|l|}{$\begin{array}{l}\text { Controlling for peer gender } \\
\text { peer nationality peer math }\end{array}$} \\
\hline major and peer GPA & No & No & No & No & No & No & Yes \\
\hline \multicolumn{8}{|l|}{ Indicators for scheduling } \\
\hline conflicts & No & No & No & No & No & Yes & Yes \\
\hline
\end{tabular}

Note. The dependent variable in all columns is the standardized course grade. All models are estimated with ordinary least squares regressions that include measures for the respective own personality trait as well as gender, nationality (Dutch and German), third-order polynomial in GPA, course-times-year fixed effects, class size, and the number of students with nonmissing personality measures. Robust standard errors clustered at the course level are in paren theses; $p$-values are reported in brackets.

TABLE A10

DETERminnNTS OF SELF-REPORTED STUdy Hours

\begin{tabular}{|c|c|c|c|c|c|}
\hline & (1) & (2) & (3) & (4) & (5) \\
\hline Persistence & $\begin{array}{l}1.2442 \\
(.102) \\
{[.000]}\end{array}$ & & & & $\begin{array}{c}1.5170 \\
(.101) \\
{[.000]}\end{array}$ \\
\hline Self-confidence & & $\begin{array}{l}.1074 \\
(.094) \\
{[.255]}\end{array}$ & & & $\begin{array}{r}-.4409 \\
(.082) \\
{[.000]}\end{array}$ \\
\hline Anxiety & & & $\begin{array}{l}.6410 \\
(.104) \\
{[.000]}\end{array}$ & & $\begin{array}{l}.6616 \\
(.106) \\
{[.000]}\end{array}$ \\
\hline Risk attitude & & & & $\begin{array}{c}-.2847 \\
(.085) \\
{[.001]}\end{array}$ & $\begin{array}{r}-.25 .37 \\
(.085) \\
{[.004]}\end{array}$ \\
\hline Observations & 8,463 & 8,463 & 8,463 & 8,463 & 8,463 \\
\hline$R^{2}$ & .123 & .104 & .108 & .104 & .133 \\
\hline
\end{tabular}

NoTE.-The dependent variable in all columns is students' self-reported weekly study hours. All models are estimated with ordinary least squares regressions that include gender, nationality (Dutch and German), third-order polynomial in GPA, course-times-year fixed effects, class size, and the number of students with nonmissing personality measures. Personality measures are standardized to mean zero and a standard deviation of one. Robust standard errors clustered at the course level are in parentheses; $p$-values are reported in brackets. 
TABLE A11

Main Results for Matiematical. Versus Nonmathematical. Courses

\begin{tabular}{|c|c|c|c|}
\hline & $\begin{array}{l}\text { All } \\
\text { Courses } \\
(1)\end{array}$ & $\begin{array}{c}\text { Mathematical } \\
\text { Courses } \\
(2)\end{array}$ & $\begin{array}{c}\text { Nonmathematical } \\
\text { Courses } \\
(3)\end{array}$ \\
\hline \multirow[t]{3}{*}{ Peer persistence } & .0175 & .0113 & .0214 \\
\hline & $(.006)$ & $(.010)$ & $(.008)$ \\
\hline & {$[.007]$} & {$[.247]$} & {$[.008]$} \\
\hline \multirow[t]{3}{*}{ Peer self-confidence } & .0011 & .0086 & -.0042 \\
\hline & $(.006)$ & $(.009)$ & $(.009)$ \\
\hline & {$[.864]$} & [..335] & {$[.648]$} \\
\hline \multirow[t]{3}{*}{ Peer anxiety } & -.0023 & .0037 & -.0073 \\
\hline & $(.005)$ & $(.007)$ & $(.007)$ \\
\hline & {$[.650]$} & {$[.626]$} & {$[.291]$} \\
\hline \multirow[t]{3}{*}{ Peer risk attitude } & -.0109 & -.0053 & -.0147 \\
\hline & $(.006)$ & $(.008)$ & $(.008)$ \\
\hline & {$[.054]$} & {$[.528]$} & {$[.061]$} \\
\hline Observations & 16,155 & 6,919 & 9,231 \\
\hline$R^{2}$ & .644 & .636 & .646 \\
\hline \multicolumn{4}{|l|}{ Controlling for peer gender nationality } \\
\hline $\begin{array}{l}\text { and high school math major } \\
\text { Indicators for scheduling conflicts }\end{array}$ & $\begin{array}{l}\text { Yes } \\
\text { Yes }\end{array}$ & $\begin{array}{l}\text { Yes } \\
\text { Yes }\end{array}$ & $\begin{array}{l}\text { Yes } \\
\text { Yes }\end{array}$ \\
\hline
\end{tabular}

NotE. The dependent variable in all columns is the standardized course grade. All columns are estimated with ordinary least squares regressions that include measures for the respective own personality trait as well as course-times-year fixed effects, gender, and nationality (Dutch, German), up to cubic polynomials for own GPA, class size, as well as number of students with nonmissing personality measures. Robust standard errors clustered at the course level are in parentheses; $p$-values are reported in brackets.

TABLE Al2

Effect of Peer Personality on Student Performance: Heterogeneous EFFects by STUdent GPA

\begin{tabular}{lc}
\hline \hline & Standardized Grade \\
& $(1)$ \\
\hline Peer persistence $\times$ high GPA & .0210 \\
& $(.009)$ \\
Peer persistence $\times$ medium GPA & {$[.029]$} \\
& .0023 \\
Peer persistence $\times$ low GPA & $(.009)$ \\
& {$[.788]$} \\
Peer self-confidence $\times$ high GPA & .0292 \\
& $(.011)$ \\
Peer self-confidence $\times$ medium GPA & {$[.009]$} \\
& .0035 \\
Peer self-confidence $\times$ low GPA & $(.011)$ \\
& {$[.745]$} \\
& .0074 \\
& $(.009)$ \\
& {$[.394]$} \\
& -.0071 \\
& $(.013)$ \\
& {$[.594]$}
\end{tabular}


TABLE A12 (Continued)

\begin{tabular}{lc}
\hline \hline & Standardized Grade \\
\hline Peer anxiety $\times$ high GPA & $(1)$ \\
& -.0013 \\
Peer anxiety $\times$ medium GPA & $(.008)$ \\
& {$[.877]$} \\
Peer anxiety $\times$ low GPA & .0057 \\
& $(.007)$ \\
& {$[.395]$} \\
Peer risk attitude $\times$ high GPA & -.0114 \\
& $(.010)$ \\
Peer risk attitude $\times$ medium GPA & {$[.268]$} \\
& .0023 \\
Peer risk attitude $\times$ low GPA & $(.015)$ \\
& {$[.881]$} \\
& -.0017 \\
Observations & $(.009)$ \\
$R^{2}$ & {$[.843]$} \\
Controlling for peer gender nation- & -.0338 \\
ality and high school math major & $(.013)$ \\
Indicators for scheduling conflicts & {$[.011]$} \\
& 16,155 \\
& .644 \\
&
\end{tabular}

NoтE. The dependent variable is the standardized course grade. Coefficients are estimated with an ordinary least squares regression that includes measures for the respective own personality trait as well as gender, nationality (Dutch and German), thirdorder polynomial in GPA, course-times-year fixed effects, class size, and the number of students with nonmissing personality measures. Additional controls include indicators for own low, medium, or high GPA. Robust standard errors clustered at the course level are in paren theses; $p$-values are reported in brackets.

\section{Appendix B}

\section{Validation of Student Motivation Scale}

This paper studies the effects of peer personality on grades. How reliable are the personality measures we use in this paper? How do our measures of personality relate to measures that are more widely used in the literature? To shed light on these two important questions, we conducted three additional surveys in 2018 among first-year economics students at the business school $(N=617)$.

\section{B1. Reliability}

To understand how reliable our personality measures are, we compute Cronbach's alphas of the traits in the first two additional surveys. The first survey was taken in the first week of the students' first course at the business school and includes the Student Motivation Scale, that is, the personality measures we use throughout this 
paper. The second survey was conducted 4 weeks later, in the fifth week of the first course, and also includes the Student Motivation Scale.

Table B1 shows the Cronbach's alphas of the traits we study in this paper. The personality psychology literature typically uses Cronbach's alphas as measures of reliability. A rule of thumb is that alphas of 0.7 or higher are considered reliable (see, e.g., Kline 2000). Our results indicate that the Cronbach's alphas for persistence and anxiety are high, ranging from 0.77 to 0.85 . The alphas in our sample are in line with those reported in the literature on related personality traits. For instance, Duckworth and Quinn (2009, 167), who introduce and validate the Short Grit Scale (Grit-S), report alphas for a subfacet of grit- "persistence of effort" - for four samples ranging between 0.60 and 0.78 . Consistent with this finding, Li et al. $(2016,93)$ report an alpha of 0.72 for this trait.

\section{B2. Relationship between Student Motivation Scale, the Big Five, and Grit}

How does our measure of persistence and other personality measures relate to measures that are used more often in the literature? To provide evidence on comparability to other measures, we conducted a third survey, 3 weeks after the second survey, which included measures of grit and Big Five personality traits conscientiousness and neuroticism. ${ }^{30}$

Table B1 shows that persistence is highly correlated with conscientiousness and grit. Are these measures merely correlated with each other, or do they in fact represent the same concept? Although correlations are often used to validate measures, these correlations do not necessarily show the extent to which the two measures are, in fact, the same.

To probe deeper into the questions of whether persistence is a facet of conscientiousness or a facet of grit and whether anxiety is a facet of neuroticism, we perform three factor analyses (see table B2).

We first perform a factor analysis with all persistence and all conscientiousness items and find that the eigenvalue of the first factor is 3.71 and that that of the second factor is 1.29. A rule of thumb commonly used in the literature is that items measure the same trait as long as the eigenvalue in the factor analysis is above one for one factor only (see Kaiser 1960). The results therefore indicate that although persistence is strongly correlated with conscientiousness, it is not a facet of conscientiousness. Our second factor analysis includes all persistence and all grit items. The eigenvalue of the first factor is 3.25, and that of the second factor is 0.92 . We therefore conclude that persistence is a facet of grit. Our third factor analysis includes all anxiety and neuroticism items. The eigenvalue of the first factor is 4.21 , and that of the second factor is 0.74 . We therefore conclude that anxiety is a facet of neuroticism.

In sum, the results indicate that our measure of persistence is in fact a measure of grit and that our measure of anxiety is a measure of neuroticism.

\footnotetext{
${ }^{30}$ Grit is measured with six items from the 12-item grit effort scale (Duckworth et al. 2007). Conscientiousness is measured with the NEO-domain (neuroticism, extraversion, and openness) 10-item IPIP (International Personality Item Pool) scale. We chose to have a lag between the measures to reduce the likelihood that students remember their answers on the first set of questions, which would have led to consistency bias.
} 


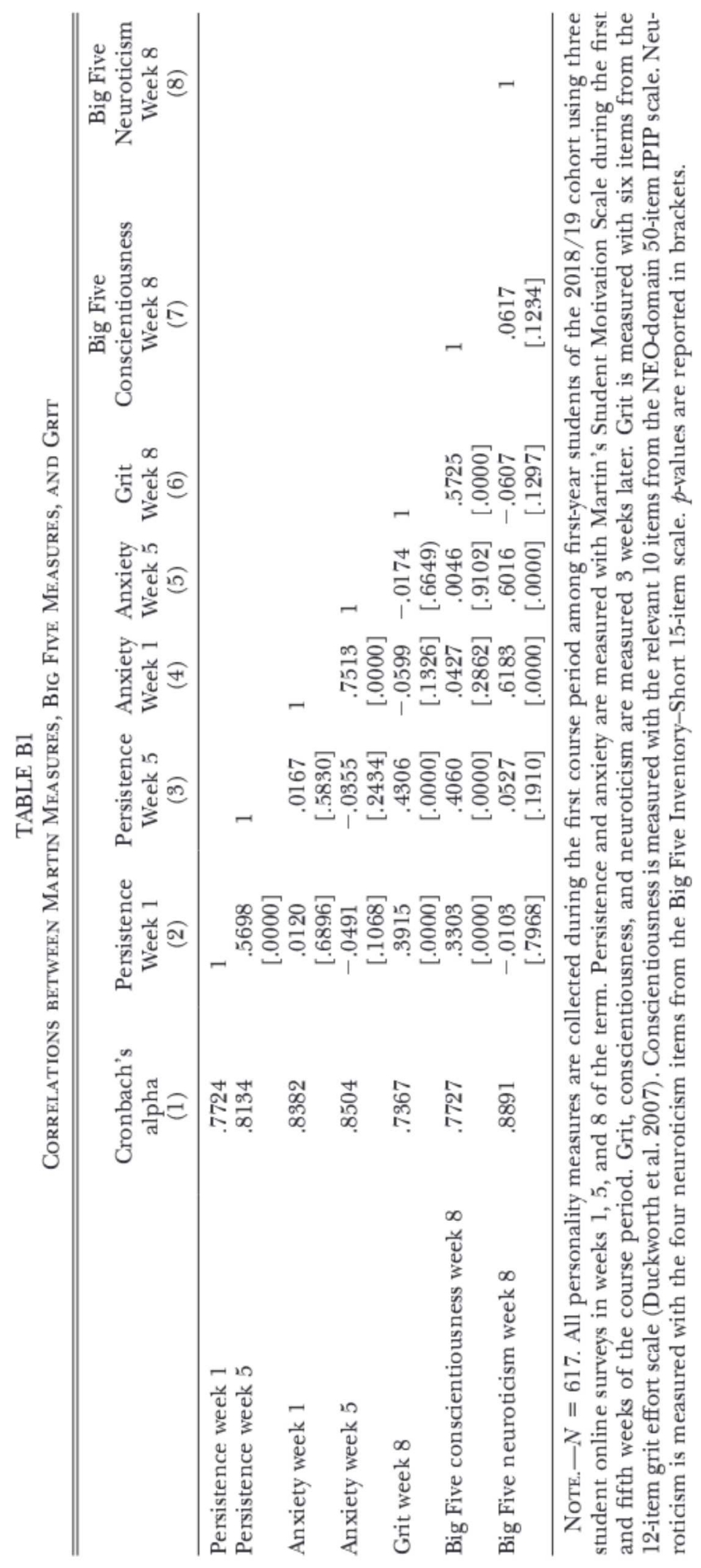


TABLE B2

Eigenvalues of Three Factor Analyses

\begin{tabular}{lccc}
\hline \hline & $\begin{array}{c}\text { Persistence and Big Five } \\
\text { Conscientiousness } \\
(1)\end{array}$ & $\begin{array}{c}\text { Persistence and } \\
\text { Grit Effort } \\
(2)\end{array}$ & $\begin{array}{c}\text { Anxiety and Big Five } \\
\text { Neuroticism } \\
(3)\end{array}$ \\
\hline Factor 1 & 3.71 & 3.23 & 4.21 \\
Factor 2 & 1.29 & .92 & .74 \\
\hline
\end{tabular}

NotE. $-N=617$. Each column reports the first two eigenvalues that result from separate factor analyses. The factor analysis reported in col. 1 includes all separate items of persistence and Big Five conscientiousness; the factor analysis in col. 2 includes all separate items of persistence and grit effort; the factor analysis in col. 3 includes all separate items of an xiety and Big Five neuroticism. Persistence is measured with Martin's Student Motivation Scale. Grit is measured with six items from the 12-item grit effort scale (Duckworth et al. 2007). Conscientiousness is measured with the NEO-domain 10-item IPIP scale. Data are collected during the first course period among first-year students of the 2018/19 cohort. Persistence and anxiety are measured during the fifth week of the course period. Grit and Big Five conscientiousness are measured 3 weeks later.

\section{References}

Åkerlund, David, Bart H. H. Golsteyn, Hans Grönqvist, and Lena Lindahl. 2016. "Time Discounting and Criminal Behavior." Proc. Nat. Acad. Sci. USA 113 (22): 6160-65.

Almlund, Mathilde, Angela Lee Duckworth, James Heckman, and Tim Kautz. 2011. "Personality Psychology and Economics." In Handbook of the Economics of Education, vol. 4, edited by Eric A. Hanushek, Stephen Machin, and Ludger Woessmann, 1-181. Amsterdam: North-Holland.

Altonji, Joseph G., Todd E. Elder, and Christopher R. Taber. 2005. "Selection on Observed and Unobserved Variables: Assessing the Effectiveness of Catholic Schools." J.P.E. 113 (1): 151-84.

Angrist, Joshua D., and Kevin Lang. 2004. "Does School Integration Generate Peer Effects? Evidence from Boston's Metco Program.” A.E.R. 94 (5): 1613-34.

Benjamini, Yoav, and Yosef Hochberg. 1995. "Controlling the False Discovery Rate: A Practical and Powerful Approach to Multiple Testing." J. Royal Statis. Soc. B 57 (1): 289-300.

Booij, Adam S., Edwin Leuven, and Hessel Oosterbeek. 2017. "Ability Peer Effects in University: Evidence from a Randomized Experiment.” Rev. Ecom. Studies 84 (2): 547-78.

Borghans, Lex, Angela Lee Duckworth, James J. Heckman, and Bas ter Weel. 2008. "The Economics and Psychology of Personality Traits." J. Human Resources 43 (4): 972-1059.

Borghans, Lex, Bart H. H. Golsteyn, James J. Heckman, and John Eric Humphries. 2016. "What Grades and Achievement Tests Measure." Proc. Nat. Acad. Sci. USA 113 (47): 13354-59.

Carrell, Scott E., Richard L. Fullerton, and James E. West. 2009. "Does Your Cohort Matter? Measuring Peer Effects in College Achievement." J. Labor Econ. 27 (3): 439-64.

Carrell, Scott E., and Mark L. Hoekstra. 2010. "Externalities in the Classroom: How Children Exposed to Domestic Violence Affect Everyone's Kids." American Econ. J.: Appl. Econ. 2 (1): 211-28.

Carrell, Scott E., Mark Hoekstra, and Elira Kuka. 2018. "The Long-Run Effects of Disruptive Peers." A.E.R. 108 (11): 3377-415. 
Carrell, Scott E., Bruce I. Sacerdote, and James E. West. 2013. "From Natural Variation to Optimal Policy? The Importance of Endogenous Peer Group Formation." Ecomometrica 81 (3): 855-82.

Chetty, Raj, John N. Friedman, and Jonah E. Rockoff. 2014. "Measuring the Impacts of Teachers II: Teacher Value-Added and Student Outcomes in Adulthood." A.E.R. 104 (9): 2633-79.

De Giorgi, Giacomo, and Michele Pellizzari. 2013. "Understanding Social Interactions: Evidence from the Class Room.” Econ. J. 124 (579): 917-53.

Dohmen, Thomas, Armin Falk, David Huffman, and Uwe Sunde. 2009. "Homo Reciprocans: Survey Evidence on Behavioral Outcomes.” Econ. J. 119 (536): $592-612$.

Dohmen, Thomas, Armin Falk, David Huffman, Uwe Sunde, Jürgen Schupp, and Gert G. Wagner. 2011. "Individual Risk Attitudes: Measurement, Determinants, and Behavioral Consequences." J. European Econ. Assoc. 9 (3): 522-50.

Donald, Stephen G., and Kevin Lang. 2007. "Inference with Difference-inDifferences and Other Panel Data." Rev. Econ. and Statis. 89 (2): 221-23.

Duckworth, Angela L., Christopher Peterson, Michael D. Matthews, and Dennis R. Kelly. 2007. "Grit: Perseverance and Passion for Long-Term Goals." J. Personality and Soc. Psychology 92 (6): 1087-101.

Duckworth, Angela Lee, and Patrick D. Quinn. 2009. "Development and Validation of the Short Grit Scale (Grit-S)."J. Persomality Assessment 91 (2): 166-74.

Duflo, Esther, Pascaline Dupas, and Michael Kremer. 2011. "Peer Effects, Teacher Incentives, and the Impact of Tracking: Evidence from a Randomized Evaluation in Kenya." A.E.R. 101 (5): 1739-74.

Elsner, Benjamin, Ingo Isphording, and Ulf Zölitz. 2018. "Achievement Rank Affects Performance and Major Choices in College." Discussion Paper no. 300, Dept. Econ., Univ. Zurich.

Falk, Armin, Anke Becker, Thomas Dohmen, Benjamin Enke, David Huffman, and Uwe Sunde. 2018. "Global Evidence on Economic Preferences." Q.J.E. 133 (4): 1645-92.

Feld, Jan, Nicolás Salamanca, and Daniel S. Hamermesh. 2016. "Endophilia or Exophobia: Beyond Discrimination.” Econ. J. 126 (594): 1503-27.

Feld, Jan, Nicolás Salamanca, and Ulf Zölitz. 2020. "Are Professors Worth It? The Value-Added and Costs of Tutorial Instructors.” J. Human Resources 55 (3): 836-63.

Feld, Jan, and Ulf Zölitz. 2017. "Understanding Peer Effects: On the Nature, Estimation, and Channels of Peer Effects." J. Labor Econ. 35 (2): 387-428.

Figlio, David N. 2007. "Boys Named Sue: Disruptive Children and Their Peers." Education 2 (4): 376-94.

Golsteyn, Bart H. H., Hans Grönqvist, and Lena Lindahl. 2014. "Adolescent Time Preferences Predict Lifetime Outcomes.” Econ. J. 124 (580): F739-F761.

Guryan, Jonathan, Kory Kroft, and Matthew J. Notowidigdo. 2009. "Peer Effect in the Workplace: Evidence from Random Groupings in Professional Golf 'Tournaments." American Econ. J: Appl. Ecom. 1 (4): 34-68.

Holland, Burt S., and Margaret D. Copenhaver. 1988. "Improved BonferroniType Multiple Testing Procedures.” Psychological Bull. 104 (1): 145-49.

Holm, Sture. 1979. "A Simple Sequentially Rejective Multiple Test Procedure." Scandinavian J. Statis. 6 (2): 65-70.

Hoxby, Caroline. 2000. "Peer Effects in the Classroom: Learning from Gender and Race Variation." Working Paper no. 7867 (August), NBER, Cambridge, MA.

Hoxby, Caroline M., and Gretchen Weingarth. 2005. "Taking Race Out of the Equation: School Reassignment and the Structure of Peer Effects." Working paper, Harvard Univ. 
Kline, Paul. 2000. The Handbook of Psychological Testing. 2nd ed. London: Routledge. Lavy, Victor, and Analia Schlosser. 2011. "Mechanisms and Impacts of Gender Peer Effects at School.” American Econ. J.: Appl. Econ. 3 (2): 1-33.

Li, Jingguang, Yajun Zhao, Feng Kong, Shuailing Du, Suyong Yang, and Song Wang. 2016. "Psychometric Assessment of the Short Grit Scale among Chinese Adolescents." J. Psychoeducational Assessment 36 (3): 91-96.

Lyle, David S. 2009. "The Effects of Peer Group Heterogeneity on the Production of Human Capital at West Point." American Econ. J.: Appl. Econ. 1 (4): 69-84.

Kaiser, Henry F. 1960. "The Application of Electronic Computers to Factor Analysis.” Educ. and Psychological Measurement 20 (1): 141-51.

Manski, Charles F. 1993. "Identification of Endogenous Social Effects: The Reflection Problem.” Rev. Econ. Studies 60 (3): 531-40.

Martin, Andrew J. 2009. "Motivation and Engagement across the Academic Life Span: A Developmental Construct Validity Study of Elementary School, High School, and University/College Students." Educ. and Psychological Measurement 69 (5): 794-824.

2011. "Courage in the Classroom: Exploring a New Framework Predicting Academic Performance and Engagement.” School Psychology Q. 26 (2): 14560 .

Oosterbeek, Hessel, and Reyn van Ewijk. 2014. "Gender Peer Effects in University: Evidence from a Randomized Experiment.” Econ. Educ. Rev. 38:51-63.

Sacerdote, Bruce. 2011. "Peer Effects in Education: How Might They Work, How Big Are They and How Much Do We Know Thus Far?" In Handbook of the Economics of Education, vol. 3, edited by Eric A. Hanushek, Stephen Machin, and Ludger Woessmann, 249-77. Amsterdam: North-Holland.

Shure, Nikki. 2017. "Non-cognitive Peer Effects in Secondary Education." Manuscript.

Šidák, Zbyněk. 1968. "On Multivariate Normal Probabilities of Rectangles: Their Dependence on Correlations.” Ann. Math. Statis. 39 (5): 1425-34.

Simes, Robert J. 1986. "An Improved Bonferroni Procedure for Multiple Tests of Significance.” Biometrika 73 (3): 751-54.

Stepner, Michael. 2013. "VAM: Stata Module to Compute Teacher Value-Added Measures." Statistical Software Components S457711, Dept. Econ., Boston Coll.

Vieider, Ferdinand M., Mathieu Lefebvre, Ranoua Bouchouicha, et al. 2015. "Common Components of Risk and Uncertainty Attitudes across Contexts and Domains: Evidence from 30 Countries.” J. European Econ. Assoc. 13 (3): 421-52.

Whitmore, Diane. 2005. "Resource and Peer Impacts on Girls' Academic Achievement: Evidence from a Randomized Experiment.” A.E.R. 95 (2): 199-203.

Zimmerman, David J. 2003. "Peer Effects in Academic Outcomes: Evidence from a Natural Experiment." Rev. Econ. and Statis. 85 (1): 9-23.

Zölitz, Ulf, and Jan Feld. 2019. "The Effect of Peer Gender on Major Choice." Discussion Paper no. 270, Dept. Econ., Univ. Zurich. 